\title{
IMPACTO DOS FATORES PESSOAIS, INSTITUCIONAIS E ESTILOS DE APRENDIZAGEM NO DESEMPENHO ACADÊMICO: UMA ANÁLISE COM ESTUDANTES DE CONTABILIDADE
}

\section{IMPACT OF PERSONAL, INSTITUTIONAL FACTORS AND LEARNING STYLES ON ACADEMIC PERFORMANCE: AN ANALYSIS WITH STUDENTS OF ACCOUNTING}

\author{
KATIA ABBAS \\ Universidade Estadual de Maringá. Endereço: Av. Colombo, $5.790 \mid \mathrm{Jd}$. \\ Universitário | 87020-900| Maringá/PR | Brasil. \\ Dhttp://orcid.org/0000-0002-6099-3206 \\ kabbas@uem.br
}

\author{
AMANDA KELEN LOPES \\ Universidade Estadual de Maringá. Endereço: Av. Colombo, $5.790 \mid J d$. \\ Universitário | 87020-900| Martingá/PR | Brasil. \\ (1) http://orcid.org/0000-0002-6389-0560 \\ amanda_k_l@hotmail.com
}

\section{RESUMO}

A pesquisa tem como objetivo verificar a influência dos fatores pessoais, institucionais e dos estilos de aprendizagem no desempenho acadêmico dos discentes de Ciências Contábeis nas disciplinas com o maior índice de reprovação de uma Instituição de Ensino Superior. A coleta de dados ocorreu por meio de questionário aplicado com os alunos do $2^{\circ}, 3^{\circ}$ e $4^{\circ}$ anos e foram obtidas 229 respostas válidas. Para testar as hipóteses, foi utilizada a estatística descritiva e multivariada (regressão). Os resultados indicam que alguns dos fatores pessoais, tais como "turno", "escola do ensino médio", "estado civil", "experiência na área", "horas de estudo extraclasse", "faixa etária", "jornada de trabalho", "membros da família", "moradia", "participação econômica familiar" e "renda familiar" apresentaram relação estatisticamente significativa com o desempenho. Dos componentes institucionais, a estratégia do projeto pedagógico do curso apresentou influência, enquanto a estrutura, o ambiente interno, o sistema técnico e a estratégia do corpo docente não foram confirmados. Por fim, os estilos de aprendizagem mostraram-se significativos apenas na disciplina de Laboratório Contábil, na qual estudantes com estilo convergente apresentaram média superior aos demais estilos. A identificação dessas variáveis (características pertinentes aos discentes e à instituição) possibilita à coordenação do curso de Ciências Contábeis e aos docentes estudarem estratégias para melhorar o resultado acadêmico dessas disciplinas, que são as que apresentam o maior índice de reprovação. A longo prazo, também espera-se contribuir para uma melhora nos índices do Exame Nacional de Desempenho dos Estudantes e no Exame de Suficiência.

Palavras-chave: Desempenho Acadêmico. Fatores Pessoais. Fatores Institucionais. Estilos de Aprendizagem. 


\begin{abstract}
The research aims to verify the influence of personal, institutional factors and learning styles on the academic performance of Accounting students in the disciplines with the highest failure rate in a Higher Education Institution. Data collection took place through a questionnaire applied to 2nd, 3rd and 4th year students, and 229 valid responses were obtained. To test the hypotheses, descriptive and multivariate statistics (regression.) were used. The results indicate that some of the personal factors, such as shift, high school, marital status, experience in the area, extra-class study hours, age group, working hours, family members, housing, family economic participation and family income, showed a statistically significant relationship with performance. Of the institutional components, the strategy of the pedagogical project of the course had an influence, while structure, internal environment, technical system and strategy of the faculty were not confirmed. Finally, the learning styles were found to be significant only in the discipline of Accounting Laboratory, in which students with convergent style had a higher average than the other styles. The identification of these variables (characteristics pertinent to students and the institution) allows the coordination of the Accounting Sciences course and teachers, to study strategies to improve the academic results of these disciplines, which are the ones with the highest failure rate. In the long run, it is also expected to contribute to an improvement in the National Student Performance Exam and Sufficiency Exam scores.
\end{abstract}

Keywords: Academic Performance. Personal Factors. Institutional Factors. Learning Styles.

\title{
1 INTRODUÇÃO
}

A educação contábil é responsável por formar profissionais competentes para o exercício das práticas contábeis (Amaro, 2014). Entretanto, o professor lida com uma diversidade de alunos dentro da sala de aula: alunos introvertidos; extrovertidos; os que apenas observam as exposições; os que anotam todas as observações expostas pelo professor; os que lidam bem com teorias; os que lidam bem com as experiências e exemplos; os que podem compreender bem por meio de imagens; os que possuem facilidade em concentrar-se; os que se dispersam facilmente; entre outros comportamentos (Nogueira, 2009; Truong, 2016).

Além da diversidade de alunos, para que as Instituições de Ensino Superior (IES) atinjam seus fins, é necessário identificar o cenário no qual operam, ou seja, como está estruturado seu ambiente para atender as prováveis variações do seu meio (Fagundes, Soler, Feliu, \& Lavarda, 2008). Existem vários fatores que se inter-relacionam e influenciam no desempenho acadêmico de um indivíduo, podendo ser relacionados a questões pessoais dos estudantes, aos professores e à instituição de ensino (Sousa, Ferreira, \& Miranda, 2019).

Quanto ao desempenho acadêmico de discentes do ensino superior, Barahona (2014) argumenta que está relacionado a duas extensões: determinantes pessoais (frequência às aulas, gênero, grau de acesso à educação, entre outros); e sociais (ambiente familiar, contexto socioeconômico, escolaridade dos pais, entre outros). Além dos determinantes pessoais e sociais, Andriola (2009), Ayeni e Adelabu (2012) afirmam que as instalações são essenciais para facilitar tanto o ensino quanto a aprendizagem dos alunos, e incluem os recursos físicos: salas de aulas adequadas, laboratórios, bibliotecas, banheiros, equipamentos, conveniências, escritórios, itens imobiliários e outros edifícios (em devidas condições de uso), considerados, neste estudo, como fatores institucionais.

Além desses fatores, a identificação dos estilos de aprendizagem dos discentes pode auxiliar os docentes no ensino, quanto à utilização de métodos que estimulem as diferentes formas de aprendizado (Nogueira, 2009; Yousef, 2016). Os estilos de aprendizagem auxiliam na identificação sobre como os alunos compreendem, interagem e respondem ao ambiente de aprendizagem, o que os torna uma ferramenta importante para professores e instituições de ensino 
(El-Hmoudova \& Milkova, 2015; Schmitt \& Domingues, 2016). Desse modo, foram desenvolvidos diversos modelos para permitir que os indivíduos sejam classificados em um tipo específico de aluno (Peter, Bacon, \& Dastbaz, 2010). Dentre os mais conhecidos, encontra-se o Kolb's learning style inventory (KLSI), de David A. Kolb, que apresenta um panorama diferente da forma de aprendizagem a partir de teorias comportamentais do aprendizado, apoiado em uma epistemologia empírica (Kolb, 1984).

Porém, conforme exposto por Sousa et al. (2019), o desempenho dos bacharéis em Ciências Contábeis nas quatro primeiras edições do Exame Nacional de Desempenho dos Estudantes (Enade) (2006, 2009, 2012 e 2015) e no Exame de Suficiência, que avaliam os conhecimentos adquiridos no curso, foi baixo, apresentando uma taxa média de aprovação de 37,24\% e 35,64\%, respectivamente. Os resultados chamam atenção, visto que são reflexos da aprendizagem dos estudantes.

Muitos pesquisadores se interessaram em estudar as diversas variáveis que afetam a aprendizagem dos estudantes (Cepeda, 2018), dentre eles, destacam-se os estudos de Araújo, Camargos, Camargos e Dias (2014), Ballester (2012), Boezerooij (2006), Cerqueira (2000), Dolado e Morales (2009), Ferreira (2015) e Rodrigues, Resende, Miranda e Ferreira (2016). Porém, os resultados ainda são divergentes e novos estudos são necessários.

O estudo de Borges (2016), por exemplo, investigou a influência dos fatores contingenciais e dos estilos de aprendizagem no desempenho acadêmico dos discentes do curso de Ciências Contábeis de uma Instituição Estadual de Educação Superior e, como limitação, a autora explica que, com a utilização do modelo VARK, não foi possível uma verificação mais direcionada dos estilos de aprendizagem predominantes, sendo necessária outra investigação.

Amaro (2014) investigou a influência de fatores contingenciais: ambiente interno (institucional); estrutura; sistema técnico; estratégia do curso (Projeto Pedagógico do Curso (PPC)); estratégia do curso (corpo docente); gênero; idade; estado civil; membros da família; moradia; jornada de trabalho; participação econômica familiar; renda familiar; nível de instrução do pai; nível de instrução da mãe; escola de ensino médio; e horas de estudo extraclasse, no ensino da Contabilidade de duas instituições federais de ensino superior. $O$ autor não observou a influência dos estilos de aprendizagem e recomenda a verificação e a validade dos construtos de sua pesquisa em outros ambientes institucionais, ou seja, a expansão do estudo para instituições de outras regiões.

Assim, além de considerar as variáveis utilizadas por Amaro (2014), este estudo acrescenta outros fatores: nota de acesso ao vestibular; forma de ingresso na instituição (por meio do Processo de Avaliação Seriada (PAS), vagas universal ou cotas sociais); e o turno cursado pelos alunos de uma IES, que já foram estudados por outros autores, mas considerando que os resultados são divergentes, são necessárias novas discussões a respeito do tema.

Com o intuito de adquirir conhecimentos sobre os fatores e os estilos de aprendizagem que podem estar influenciando no desempenho dos discentes ou até mesmo na desistência deles em disciplinas do curso de Ciências Contábeis, este estudo apresenta a seguinte questão de pesquisa: qual a influência dos fatores pessoais e institucionais e dos estilos de aprendizagem no desempenho acadêmico dos discentes de Ciências Contábeis nas disciplinas com o maior índice de reprovação de uma IES? Por sua vez, o objetivo é verificar a influência dos fatores pessoais, institucionais e dos estilos de aprendizagem no desempenho acadêmico dos discentes de Ciências Contábeis nas disciplinas com o maior índice de reprovação de uma IES.

O conhecimento desses fatores associados ao desempenho permitirá aos responsáveis elaborarem políticas, objetivando melhorar a qualidade acadêmica dos discentes (Barahona, 2014). Além disso, uma das preocupações do meio acadêmico é o "sucesso" dos discentes no Enade, pelo fato de ser um indicador que representa a qualidade do ensino e também por indicar os fatores que interferem no alcance do bom desempenho e em seu aperfeiçoamento (Magdalena, 2015). Analisar o desempenho dos estudantes e as decorrências dos diferentes fatores envolvidos é uma forma de controle e condução dos efeitos que a educação proporciona (Hromcová \& Agnese, 2018; 
Magdalena, 2015). Sendo assim, conhecer os fatores que interferem no desempenho dos discentes demonstra implicações para a aprendizagem e sucesso dos alunos (Magdalena, 2015).

Com o desenvolvimento deste estudo, pretende-se identificar as variáveis que explicam o desempenho dos discentes, para que a coordenação e os docentes possam traçar estratégias, considerando que serão analisadas as disciplinas do curso que apresentam o maior índice de reprovação. A longo prazo, também se espera uma melhora nos índices do Enade e do Exame de Suficiência.

\section{REFERENCIAL TEÓRICO}

\subsection{Estilos de Aprendizagem}

A Psicologia é responsável pelos primeiros estudos sobre os estilos de aprendizagem (Branco, 2010), e, quanto à definição do termo "estilos de aprendizagem", os pesquisadores não entraram em um consenso (Yanardöner, Kiziltepe, Seggie, \& Sekerler, 2014). Keefe e Ferrell (1990) referem-se ao termo como sendo uma gestalt que adequa ações internas e externas vindas da neurobiologia, da personalidade e do processo de crescimento do indivíduo e que refletem no seu comportamento.

Por outro lado, DeBello (1990, p. 203) sintetiza o termo "estilos de aprendizagem" como sendo "a forma como as pessoas absorvem, processam e retêm informações". Sob a perspectiva de Lopes (2002), os estilos de aprendizagem não são "bons" ou "ruins", representam um modo preferencial de aprendizagem, enquanto Bergil (2017) expõe que estão relacionados com a maneira que os indivíduos desejam utilizar suas habilidades.

Assumindo que existem diferentes estilos de aprendizagem, é conveniente, após identificálos, combiná-los com diversas formas de ensino, recursos e planos de aprendizagem (Coffield, Moseley, Hall, \& Ecclestone, 2004). Assim, o conhecimento é adquirido, internalizado e utilizado de forma que alcance valor no âmbito de aprendizagem situado (Hsu, 2017), pois, quando o conteúdo ensinado aos alunos é exposto de forma que combine com o estilo de aprendizagem deles, além de interferir no desempenho acadêmico, intervém também na atitude em relação ao aprendizado (Cheng, Chiu, Wu, \& Tsaih, 2017).

Não são apenas os estudantes que aprendem de formas diferentes, os métodos que os professores utilizam para ensinar também variam (Felder \& Silverman, 1988). Portanto, é necessário que ministrem aulas considerando os diferentes estilos de aprendizagem (Coffield et al., 2004). Alguns docentes ministram aulas expositivas, outros demonstram ou discutem, alguns realizam aplicações práticas, outros enfatizam a memória e a compreensão, ou seja, o quanto o estudante aprende durante uma aula é orientado pela compatibilidade de seu estilo de aprendizagem e do estilo que o professor ensina (Felder \& Silverman 1988).

Os estilos de aprendizagem dos alunos e os fatores que influenciam suas preferências de aprendizagem têm sido utilizados em inúmeros estudos publicados em periódicos nas últimas décadas (Yousef, 2016). Considerando o interesse em pesquisas neste sentido e, ainda, que os discentes possuem preferências quanto ao processo de aprendizagem, foi desenvolvida uma variedade de modelos para identificar e avaliar os estilos de aprendizagem.

Coffield et al. (2004) identificaram 71 modelos de estilos de aprendizagem e, após critérios adotados, categorizaram 13 modelos como principais. Dentre os modelos existentes, o instrumento desenvolvido por Kolb em 1969, 1985, 1993, 1999, 2005 é utilizado para estudantes universitários (Cerqueira, 2000).

Conforme McCarthy (2010), a Teoria de Aprendizagem Experiencial (TAE), de David A. Kolb, e o instrumento baseado nessa teoria (Inventário de Estilos de Aprendizagem (IEA)) são a teoria e o instrumento mais utilizados em pesquisas. Além disso, a proposta de Kolb é uma das que mais exerceu influência em trabalhos realizados sobre modelos para identificar os estilos de aprendizagem (Coffield et al. 2004). Sendo assim, e considerando que o objetivo desta pesquisa é estudar os estilos de aprendizagem de estudantes universitários, foi escolhido o modelo de Kolb. 
David A. Kolb desenvolveu a TAE utilizando bases científicas teóricas e investigações decorrentes de pesquisadores anteriores, com início em investigações sobre desenvolvimento do pensamento e conhecimento (Cerqueira, 2000). A teoria baseia-se em trabalhos de pesquisadores do século XX - nomeadamente John Dewey, Kurt Lewin, Jean Piaget, William James, Carl Jung, Paulo Freire, Carl Rogers, dentre outros (Cerqueira, 2000; Kolb \& Kolb, 2005).

Kolb (1984, p. 38) considera que a TAE define a aprendizagem como sendo "o processo pelo qual o conhecimento é criado através da transformação da experiência". A aprendizagem experiencial é um processo de construção do conhecimento, passando por um ciclo de quatro estágios (McCarthy, 2010). As quatro etapas do ciclo de aprendizagem, ou seja, os quatro modos de aprendizagem, podem ser entendidos conforme Tabela 1.

\section{Tabela 1}

As quatro etapas do ciclo de aprendizagem e suas principais características

\section{Experiência Concreta (EC)}

Nessa etapa, o estudante tende a confiar mais em seus sentimentos do que em um enfoque sistemático dos problemas e situações. Tende a ser mais sensível aos sentimentos das outras pessoas. Em ambiente de aprendizagem, confia mais em sua capacidade de adaptação às mudanças.

\section{Observação Reflexiva (OR)}

Observa cuidadosamente antes de fazer um juízo e busca significado das coisas. Em situação de aprendizagem, o estudante confia na paciência, na objetividade e nos próprios pensamentos e sentimentos para formular opiniões.

\section{Conceituação Abstrata (CA)}

Envolve a utilização da lógica e das ideias, mais do que o uso dos sentimentos. Em geral, confia na planificação sistemática e desenvolve teorias e ideias para resolver problemas, atuando de forma intelectual em uma situação.

\section{Experimentação Ativa (EA)}

Habilidade para cumprir tarefas. A aprendizagem é de forma ativa, o estudante experimenta com a intenção de influenciar ou modificar situações, tem interesse em coisas que realmente funcionam em oposição à mera observação de uma situação. Admira o cumprimento das coisas e gosta de ver os resultados de sua influência.
Palavra que representa o modo de aprendizagem

- Sentir.

\section{Atividades}

Laboratórios, observações, leitura de texto primário, simulações/jogos, filmes, trabalho de campo e exemplos.

Palavra que
representa o modo
de aprendizagem
- Observar.

\section{Atividades}

Perguntas para reflexão, discussões, questões retóricas, jornais.

Fonte: Adaptado de Cerqueira (2000), Kolb (1984) e Svinicki e Dixon (1987).

Conforme apresentado na Figura 1, o modelo é descrito por duas dimensões opostas polares da Experiência Concreta (EC) e da Conceituação Abstrata (CA) e duas dimensões opostas da Observação Reflexiva (OR) e Experimentação Ativa (EA).

No ciclo de aprendizagem, existem duas dimensões de aprendizagem diferentes, sendo que a primeira é a percepção, ou seja, algumas pessoas percebem melhor a informação por meio da experiência concreta (tocar, ver, ouvir) e outras percebem melhor de forma abstrata (conceitos mentais ou visuais), constituindo-se, assim, a oposição CA × EC (Silva, 2006). A segunda diz respeito ao processamento, ou seja, algumas pessoas processam melhor as informações fazendo alguma experimentação, enquanto outras processam melhor pela observação reflexiva (pensando sobre as coisas), fazendo-se, assim, a oposição EA × OR (Silva, 2006).

Por mais que a aprendizagem seja formada pelas quatro habilidades, devido às experiências de vida, demanda ambiental e genética, os indivíduos desenvolvem uma maneira dominante em cada uma das dimensões e, ao utilizar certas habilidades mais que as outras, determina-se o estilo de aprendizagem (Kolb \& Kolb, 2008; Leitão, 2006). Após realizar a identificação entre ser concreto ou abstrato e entre ser ativo ou reflexivo, o instrumento possibilita a identificação dos 
estilos de aprendizagem individuais em quatro categorias de estudantes: divergente, acomodador, assimilador e convergente (Kolb \& Kolb 2008; McCarthy, 2010).

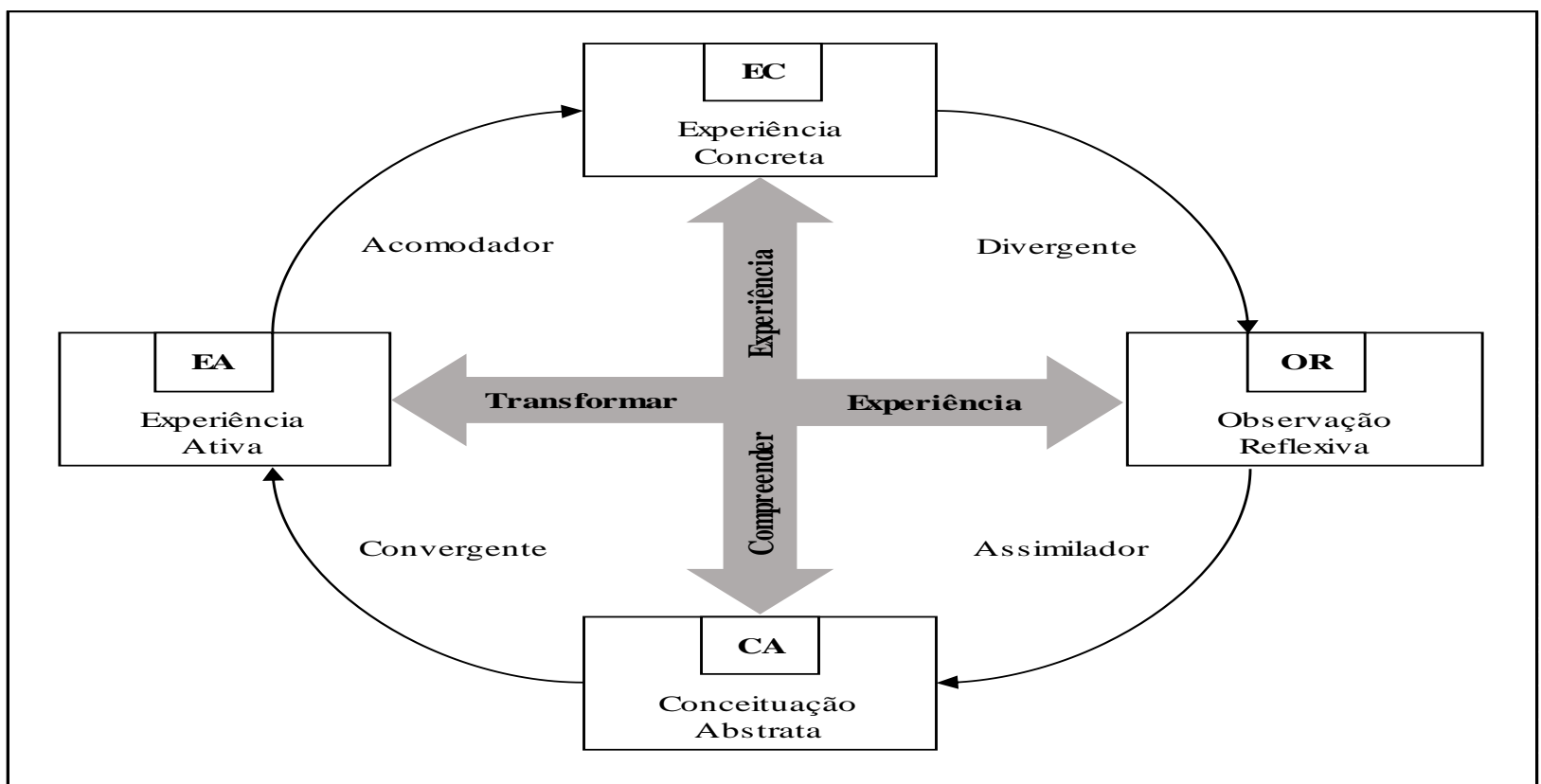

Figura 1. O ciclo de aprendizagem experiencial

Fonte: Adaptado de Kolb (1984).

A característica predominante dos divergentes é a capacidade imaginativa, geração de ideias (brainstorming) e consciência de valores, além disso, gostam de coletar informações e, em situações formais de aprendizagem, possuem interesse em trabalhar em grupo, gostam de envolver-se com pessoas, são sentimentais, possuem amplo interesse cultural, tendendo a qualificar-se nas artes (Kolb, 1984; Kolb \& Kolb, 2005).

Os indivíduos com o estilo de aprendizagem acomodador são objetivos, ou seja, possuem habilidades de aprender com a experiência "prática" (Kolb \& Kolb, 2005; McCarthy, 2010). São opostos aos assimiladores e enfatizam a EC e a EA (Kolb, 1984). O principal atributo do estilo acomodador é que eles fazem planos, envolvem-se em novas e desafiadoras oportunidades, testando novas abordagens e são adaptativos a mudanças imediatas, ademais, preferem realizar tarefa com outras pessoas, desenvolver trabalhos de campo, são mais orientados para a "ação", sendo pessoas com preferência na área de marketing ou vendas (Kolb, 1984; Kolb \& Kolb, 2005).

As competências dominantes na CA e OR são dos indivíduos com estilo de assimilação (Kolb, 1984; Kolb \& Kolb, 2005). São melhores em compreender muitas informações e colocálas de modo conciso e lógico e, diferente dos acomodadores, são menos focados em pessoas e mais voltados para ideias, preferindo palestras, leituras, gostam de pensar sobre coisas e modelos analíticos, sendo este estilo interessante para a área de informação e ciência (Kolb, 1984, Kolb \& Kolb, 2005).

Já o estilo de aprendizagem convergente consiste na habilidade principal da CA e da EA (Kolb, 1984; Kolb \& Kolb, 2005). A resolução de problemas, tomada de decisões e execução de ideias práticas são dominantes em indivíduos com esse estilo. Possuem preferências em lidar com tarefas técnicas em vez de assuntos sociais e interpessoais, gostam de novas ideias, simulações, sendo habilidades importantes em profissões relacionadas com a tecnologia (Kolb, 1984; Kolb \& Kolb, 2005).

A partir da TAE, foi projetado o Inventário de estilo de aprendizagem - tradução para KLSI - para medir o grau no qual os indivíduos apresentam os diversos estilos de aprendizagem (Kolb \& Kolb, 2005). O instrumento é, em si, uma explicação operacional da teoria (Kolb \& Funk, 2002). Existem cinco versões do learning style inventory (LSI) e todas apresentam um breve questionário com nove itens para Kolb Learning Style Inventory (KLSI), versão 1, obra criada em 
1969, e 12 itens para as versões seguintes, solicitando aos respondentes que classifiquem quatro finais de sentenças que retratam as quatro maneiras de aprendizagem - EC, OR, CA e EA (Kolb \& Kolb, 2005).

Quanto ao uso do método em pesquisas, Kolb e Kolb (2008) citaram alguns estudos, como o de Clarke (1977), Jervis (1983), Loo (2002) e Rowe e Waters (1992), e concluíram que os contadores tendem a ser convergentes, porém pesquisas realizadas no Brasil apresentaram outros resultados. Hamann (2011) e Nogueira, Espejo, Reis e Voese (2012) demonstraram que os alunos do curso de Ciências Contábeis tendem a ser assimiladores. Da mesma maneira, Santos, Colauto, Gassner, Antonovz e Correa (2014) observaram, em sua pesquisa, que os perfis assimiladores e acomodadores eram dominantes em alunos de Contabilidade (Graduação, Especialização e Mestrado). Barbosa (2017) também identificou o perfil assimilador predominante nos alunos de Contabilidade que participaram de sua amostra.

Na Europa, um estudo realizado na Universidade de Aksaray por Polat, Peker, Özpeynirci e Duman (2015) mediu a influência dos estilos de aprendizagem no desempenho dos estudantes de Ciências Contábeis e constatou que os alunos não têm o mesmo modo de aprender e traços de personalidade, sugerindo que há diferenças individuais durante a aprendizagem. Ressaltaram que é necessário que os professores sejam informados sobre os estilos dos alunos, a fim de determinar métodos de ensino, abordagens e materiais, considerando os diferentes estilos de aprendizagem. Os autores adaptaram o inventário desenvolvido por Honey e Munford de 1992, que, segundo eles, foi o que inspirou a TAE de David A. Kolb, e encontraram uma relação entre os estilos de aprendizagem e o desempenho, concluindo que os alunos pragmatistas apresentam desempenho maior em relação aos outros. O estilo pragmatista corresponde aos indivíduos que gostam de discutir em grupos, agir de forma prática (Polat et al., 2015) e assemelham-se aos divergentes e convergentes.

A partir das divergências encontradas nos estudos citados e da importância da identificação dos estilos de aprendizagem dos discentes, tem-se a seguinte hipótese de pesquisa: Há influência estatisticamente positiva e significativa dos estilos de aprendizagem no desempenho dos alunos.

\subsection{Fatores Pessoais, Institucionais e o Desempenho}

O objetivo de alcançar bons resultados e reduzir o número de alunos desistentes do curso é uma preocupação constante de muitas instituições de ensino superior (Pérez, Pérez-López, \& Rodríguez-Ariza, 2011). Além disso, o ensino é um serviço que busca desenvolver as competências dos alunos, sendo a eficiência do setor educacional normalmente determinada pelo seu impacto no desempenho dos estudantes (Win \& Miller, 2005).

A identificação do efeito das variáveis sobre os discentes e seu desempenho é uma ferramenta auxiliar para que as instituições de ensino tomem providências corretivas ou preventivas acerca do ensino (Amaro, 2014). É de interesse não só dos professores, mas também dos coordenadores, consultores pedagógicos e alunos, estudos que apresentam a compreensão a respeito do desempenho dos discentes, assim como as variáveis impactantes que podem interferir em seus resultados (Andrade \& Corrar, 2008).

Win e Miller (2005) afirmam que o desempenho dos estudantes pode ser visto a partir de dois fatores: (i) um com origem no indivíduo: a ligação entre os elementos socioeconômicos e de habilidades de cada acadêmico; (ii) e o outro tendo sua origem na instituição de ensino: como é transmitido e organizado o conhecimento dentro dessas instituições.

Relacionado aos fatores pessoais dos discentes, Araújo et al. (2014) identificaram se o desempenho (mensurado por meio da nota final nas disciplinas) de estudantes de Contabilidade de uma Universidade de Belo Horizonte é explicado pelas variáveis: frequência às aulas; idade; gênero; natureza da disciplina (qualitativa ou quantitativa); tipo de disciplina (formação básica ou específica); e situação ao final da disciplina (aprovado, reprovado ou trancamento). Como conclusões, constataram que o número de faltas não interferiu no desempenho, apresentando, 
inclusive, uma melhora nas disciplinas qualitativas, e que os alunos menos jovens apresentaram um melhor desempenho, os alunos do gênero feminino apresentaram notas maiores do que os do gênero masculino e os discentes apresentaram maiores notas em disciplinas qualitativas e nas específicas do curso.

Kamal, Asrar, Younes e Chishti (2014) desenvolveram um estudo na Ásia e analisaram alguns fatores que poderiam estar relacionados ao baixo desempenho dos estudantes. Um dos fatores analisados foi o perfil econômico dos alunos, que demonstrou uma relação estatisticamente significativa com o desempenho dos estudantes, concluindo, assim, que a "pobreza" dos alunos afeta seu desempenho. As variáveis explicativas "contribuição dos professores" e "contribuição dos pais" também indicaram sinais positivos, sugerindo que essas variáveis têm influência sobre o desempenho dos alunos.

Em resumo, no campo das características pertinentes ao indivíduo, pesquisas nacionais e internacionais têm demonstrado que a idade (Araújo et al., 2014; Caiado \& Madeira, 2002; Guney, 2009), o gênero (Baccaro, 2014; Campbell, 2007; Ferreira, 2015; Oliveira, 2011), a renda (Amaro, 2014; Kamal et al., 2014; Oliveira, 2011) e a performance anterior (Caballero, Ruiz, Rodríguez, \& Ruiz, 2015; Baccaro, 2014; Caiado \& Madeira, 2002) explicam o desempenho dos discentes.

Considerando que as características e diferenças pessoais de cada um são fatores que podem influenciar no desempenho dos alunos (Amaro, 2014; Borges, Miranda, \& Freitas, 2017; Ferreira, 2015; Uribe, Gómez, \& Elorza, 2011,), foi elaborada a seguinte hipótese de pesquisa: Existem diferenças estatisticamente significativas entre o desempenho dos alunos com fatores pessoais na instituição de ensino. Esta hipótese foi subdividida nas seguintes:

- Existem diferenças estatisticamente significativas entre o desempenho dos alunos com a forma de ingresso na instituição;

- Existem diferenças estatisticamente significativas entre o desempenho dos alunos com o turno e a escola frequentada durante o ensino médio;

- Existem diferenças estatisticamente significativas entre o desempenho dos alunos com a experiência na área e a jornada de trabalho;

- Existem diferenças significativas no rendimento acadêmico de acordo com as horas de estudo extraclasse;

- Existem diferenças significativas no rendimento acadêmico de acordo com o gênero, a faixa etária e o estado civil dos alunos;

- Existem diferenças significativas no rendimento acadêmico de acordo com a quantidade de membros da família e com o nível de instrução do responsável; e

- Existem diferenças significativas no rendimento acadêmico conforme a participação econômica familiar e a renda familiar.

Quanto aos fatores institucionais (ambiente interno, estrutura, sistema técnico, PPC e estratégia do corpo docente), Paiva e Lourenço (2011) destacam a importância de um ambiente em que os alunos sintam-se à vontade e seguros para apresentar suas ideias e que possam perceber um progresso efetivo em sua aprendizagem. Ademais, os autores afirmam que, em um ambiente de boa convivência, o aluno facilmente expõe suas dúvidas, melhorando, assim, a aprendizagem.

Em relação ao ambiente interno, Rodrigues (2016) assinala que, dentre as variáveis significativas que explicam o rendimento dos alunos, encontram-se a titulação do coordenador e o incentivo à participação em iniciação científica, em eventos e em congressos, o que reforça a importância da qualificação profissional e da interação entre a coordenação e os alunos.

Amaro (2014) identificou, em seu estudo, uma relação estatisticamente positiva e significativa do fator "ambiente interno" com o desempenho dos discentes. Por outro lado, Borges (2016) buscou verificar essa mesma relação e concluiu que a hipótese não pôde ser testada, sugerindo ajustes no constructo para uma futura análise. Com isso, por meio da percepção dos alunos, diante da atenção recebida por eles do chefe do departamento, coordenador do curso, corpo docente e funcionários, foi elaborada a seguinte hipótese de pesquisa: Há influência 


\section{estatisticamente positiva e significativa do fator "ambiente interno" no desempenho dos alunos.}

Existem instalações que são essenciais para facilitar a aprendizagem dos alunos, que incluem os recursos físicos, como salas de aulas adequadas, laboratórios, bibliotecas, banheiros, equipamentos, conveniências, escritórios, itens imobiliários etc. (em devidas condições de uso) (Andriola, 2009; Ayeni \& Adelabu, 2012). Embora Andriola (2009) tenha observado que o ambiente educacional (salas de aula, bibliotecas, laboratórios, ambientes de trabalho e de estudo) exerce influência no desempenho dos alunos, Amaro (2014) e Borges (2016) não encontraram influência estatisticamente positiva do fator estrutura no desempenho dos discentes.

Hill e Epps (2010) também analisaram a influência do ambiente da sala de aula na percepção de acadêmicos de Administração e sua satisfação com a estrutura. 237 estudantes responderam ao questionário e, apesar dos alunos avaliarem como positivo o aproveitamento do curso e da aprendizagem em sala de aula quando a infraestrutura é adequada, os autores analisaram as notas esperadas no curso e concluíram que as características do ambiente não afetaram o desempenho. Considerando a importância de um ambiente adequado, foi elaborada a seguinte hipótese: Há influência estatisticamente positiva e significativa do fator "estrutura" no desempenho dos alunos.

Outro fator que afeta significativamente o ambiente educacional é a tecnologia (Douglass, 2005; Stoll, Fink, \& Earl, 2005), que pode estar relacionada positivamente com os rendimentos dos alunos, incluindo o desempenho (Hurst, 2005). Stoll et al. (2005) ponderam que a tecnologia combinada com habilidades de investigação e análise crítica torna-se uma importante ferramenta para o processo de aprendizagem e estimula os alunos a explorarem e compreenderem o mundo ao seu redor.

Existem áreas de integração tecnológica que possuem efeito positivo no desempenho de alunos de instituições de ensino (Amaro, 2014). Esse efeito pode ser observado em quatro áreas de integração tecnológica que devem ser testadas, que são (i) ensino e aprendizagem; (ii) desenvolvimento profissional dos educadores; (iii) administração e apoio; e (iv) infraestrutura (Weathersbee, 2008; Amaro, 2014). Amaro (2014) encontrou influência estatisticamente significativa entre o sistema técnico com o desempenho dos alunos, enquanto Borges (2016) não encontrou relação. Com isso, foi elaborada a seguinte hipótese: Há influência estatisticamente positiva e significativa do fator "sistema técnico" no desempenho dos alunos.

Outro elemento que merece destaque é o PPC, que apresenta aspectos relevantes relacionados à instituição de ensino, como: políticas acadêmicas direcionadas para o ensino de Graduação e Pós-Graduação; incentivo à pesquisa e à extensão; adequação dos conteúdos ministrados; métodos pedagógicos orientados para instruir; e os sistemas de avaliação de aprendizagem (Soares, 2002; Andriola, 2009). As estratégicas desenvolvidas no PPC estão relacionadas com a utilização adequada dos recursos tecnológicos, financeiros, físicos e humanos, para, assim, evitar problemas institucionais (Amaro, 2014).

Borges (2016) identificou uma relação positiva entre o fator "PPC" com o desempenho dos alunos. Amaro (2014) também apontou influência estatisticamente positiva e significativa entre os mesmos fatores. A partir disso, foi elaborada a seguinte a hipótese: Há influência estatisticamente positiva e significativa do fator "PPC" no desempenho dos alunos.

Os docentes devem considerar os recursos educacionais e materiais necessários para a instrução em diversas disciplinas, tanto quantitativas quanto qualitativas (Andriola, 2009). Além disso, as ferramentas e estratégias de ensino empregadas pelos professores devem motivar e envolver os alunos para a aprendizagem (Mazzioni, 2013). A atuação do docente em sala de aula, sua qualificação, a forma de condução de aula e o domínio de conteúdo ministrado podem influenciar o desempenho dos discentes (Miranda, 2011; Amaro, 2014). Borges (2016) constatou influência do fator "estratégia do corpo docente" no desempenho dos estudantes, enquanto Amaro (2014) concluiu que não existe influência. Os resultados contraditórios levam à hipótese: Há influência estatisticamente positiva e significativa do fator "estratégia do corpo docente" no desempenho dos alunos. 
A Tabela 2 apresenta os resultados de mais alguns estudos nacionais e internacionais que abordaram a influência dos fatores pessoais e/ou institucionais no desempenho dos estudantes. Na terceira coluna, estão os achados dos estudos, ou seja, as variáveis que apresentaram influência no desempenho, entre elas, destacam-se os fatores pessoais dos alunos, tais como gênero e turno. Porém outras variáveis, não muito exploradas, também explicam o desempenho, como, por exemplo, a participação em atividades acadêmicas (iniciação científica, empresa júnior, monitoria), atributos da coordenação de curso e o aluno ser ou não cotista.

\section{Tabela 2}

Resumo dos estudos

\begin{tabular}{|c|c|c|}
\hline $\begin{array}{l}\text { Autor(es) (Ano), } \\
\text { País }\end{array}$ & Objetivo & Variáveis que influenciam no desempenho \\
\hline $\begin{array}{l}\text { Oliveira (2011), } \\
\text { Brasil }\end{array}$ & $\begin{array}{l}\text { Examinar os fatores que influenciam no } \\
\text { desempenho acadêmico dos estudantes da } \\
\text { Universidade Federal da Paraíba (UFPB). }\end{array}$ & $\begin{array}{l}\text { Gênero, escola do ensino médio, renda } \\
\text { familiar, nível de instrução dos pais, trabalho } \\
\text { e estado civil. }\end{array}$ \\
\hline $\begin{array}{l}\text { Miranda (2011), } \\
\text { Brasil }\end{array}$ & $\begin{array}{l}\text { Investigar a relação entre o desempenho } \\
\text { discente e a qualificação docente } \\
\text { (acadêmica, profissional e pedagógica) em } \\
\text { Ciências Contábeis. }\end{array}$ & $\begin{array}{l}\text { Qualificação docente acadêmica (preparação } \\
\text { do docente para a pesquisa). }\end{array}$ \\
\hline $\begin{array}{l}\text { Baccaro (2014), } \\
\text { Brasil }\end{array}$ & $\begin{array}{l}\text { Analisar a relação entre o desempenho no } \\
\text { vestibular e o rendimento acadêmico dos } \\
\text { alunos de uma universidade pública } \\
\text { paulista. }\end{array}$ & $\begin{array}{l}\text { Desempenho no vestibular, gênero, raça, } \\
\text { quantidade de bens, ensino fundamental, } \\
\text { ensino médio e quantidade de vestibulares. }\end{array}$ \\
\hline $\begin{array}{l}\text { Ferreira }(2015), \\
\text { Brasil }\end{array}$ & $\begin{array}{l}\text { Identificar as variáveis significativas na } \\
\text { explicação do resultado Enade } 2012 \mathrm{em} \\
\text { Ciências Contábeis. }\end{array}$ & $\begin{array}{l}\text { Nível aluno: gênero, estado civil, etnia, } \\
\text { renda, bolsa de estudo, forma de ingresso, } \\
\text { escolaridade da mãe, escola ensino médio } \\
\text { (pública ou privada), tipo de ensino médio } \\
\text { (tradicional ou profissionalizante), } \\
\text { quantidade de livros, horas estudadas, } \\
\text { iniciação científica, monitoria, atividades de } \\
\text { extensão; e } \\
\text { Nível instituição: categoria administrativa da } \\
\text { IES, região, número de concluintes } \\
\text { participantes do Enade, nota de ingressantes } \\
\text { (por meio do Exame Nacional do Ensino } \\
\text { Médio (ENEM)), percentual de mestres, } \\
\text { percentual de infraestrutura e percentual de } \\
\text { organização didático-pedagógica. }\end{array}$ \\
\hline $\begin{array}{l}\text { Pereira (2017), } \\
\text { Brasil }\end{array}$ & $\begin{array}{l}\text { Investigar se existe diferença no } \\
\text { desempenho acadêmico entre cotistas e } \\
\text { não cotistas na conclusão do curso de } \\
\text { Graduação nas universidades federais da } \\
\text { região Nordeste no Enade. }\end{array}$ & Cotas sociais. \\
\hline $\begin{array}{l}\text { Borges (2017), } \\
\text { Brasil }\end{array}$ & $\begin{array}{l}\text { Analisar as relações entre o desempenho } \\
\text { acadêmico e a motivação dos estudantes } \\
\text { do curso de Ciências Contábeis de uma } \\
\text { universidade pública. }\end{array}$ & $\begin{array}{l}\text { Turno, participação em atividades } \\
\text { acadêmicas (iniciação científica, empresa } \\
\text { júnior, monitoria) e trabalho. }\end{array}$ \\
\hline $\begin{array}{l}\text { Caiado e Madeira } \\
\text { (2002), Portugal }\end{array}$ & $\begin{array}{l}\text { Determinar os fatores demográficos e } \\
\text { acadêmicos relevantes na nota final do } \\
\text { curso de Contabilidade. }\end{array}$ & Idade e nota do vestibular. \\
\hline $\begin{array}{l}\text { Win e Miller } \\
\text { (2005), Austrália }\end{array}$ & $\begin{array}{l}\text { Examinar os fatores que influenciam o } \\
\text { desempenho acadêmico dos estudantes } \\
\text { universitários, concentrando-se no papel } \\
\text { dos antecedentes e dos fatores escolares. }\end{array}$ & $\begin{array}{l}\text { Escolas de ensino médio e características } \\
\text { próprias dos alunos. }\end{array}$ \\
\hline
\end{tabular}




\begin{tabular}{l|l|l}
\hline $\begin{array}{l}\text { Arquero, Byrne, } \\
\text { Flood e Gonzalez } \\
(2009),\end{array}$ & $\begin{array}{l}\text { Analisar a influência de fatores intrínsecos } \\
\text { e vocacionais sobre o desempenho } \\
\text { Espanha } \\
\text { Contabilidade. }\end{array}$ & $\begin{array}{l}\text { Gênero, interesse pela Contabilidade, } \\
\text { experiência do assunto na escola, } \\
\text { autoconfiança acadêmica e índices de acesso } \\
\text { à universidade. }\end{array}$ \\
\hline $\begin{array}{l}\text { Garkaz, Banimahd } \\
\text { e Esmaeili (2011), } \\
\text { Irã }\end{array}$ & $\begin{array}{l}\text { Estudar quais fatores podem afetar o } \\
\text { desempenho acadêmico. }\end{array}$ & Gênero, tipo de diploma e trabalho. \\
\hline $\begin{array}{l}\text { Uribe } \text { et al. }(2011), \\
\text { Colômbia }\end{array}$ & $\begin{array}{l}\text { Identificar os fatores que podem estar } \\
\text { associados à perda do status do aluno } \\
\text { devido ao baixo desempenho acadêmico. }\end{array}$ & $\begin{array}{l}\text { Gênero, turno, escola do ensino médio, } \\
\text { moradia e forma de ingresso. }\end{array}$ \\
\hline $\begin{array}{l}\text { Ballester (2012), } \\
\text { Espanha }\end{array}$ & $\begin{array}{l}\text { Examinar o efeito que exercem os fatores } \\
\text { demográficos, institucionais, econômicos } \\
\text { e acadêmicos sobre o desempenho } \\
\text { acadêmico dos alunos. }\end{array}$ & $\begin{array}{l}\text { Nota de acesso à universidade, curso que o } \\
\text { aluno está cursando, gênero, disciplinas } \\
\text { anteriormente frequentadas, permanência do } \\
\text { professor na universidade e turno. }\end{array}$ \\
\hline $\begin{array}{l}\text { Wentworth e } \\
\text { Middleton (2014), } \\
\text { Estados Unidos }\end{array}$ & $\begin{array}{l}\text { Investigar o uso da tecnologia, gênero e } \\
\text { status de emprego no desempenho } \\
\text { acadêmico. }\end{array}$ & Gênero e trabalho. \\
\hline $\begin{array}{l}\text { Chies, Graziosi e } \\
\text { Pauli (2014), Itália }\end{array}$ & $\begin{array}{l}\text { Analisar os fatores que influenciam o } \\
\text { abandono no segundo ano do bacharelado } \\
\text { na Universidade de Trieste. }\end{array}$ & Gênero e trabalho. \\
\hline Fons:
\end{tabular}

Fonte: elaborado pelas autoras.

\section{METODOLOGIA}

\subsection{Procedimentos Éticos}

Conforme a Resolução n ${ }^{\circ}$ 466, de 12 de dezembro de 2012, do Conselho Nacional de Saúde (CNS), as pesquisas que envolvem seres humanos devem respeitar os fundamentos éticos e científicos pertinentes. Com isso, em respeito aos participantes e sua autonomia, o estudo foi submetido a um Comitê Permanente de Ética em Pesquisa com Seres Humanos (Copep).

Os documentos exigidos (projeto de pesquisa, brochura de pesquisa, questionário, autorização do departamento em que a pesquisa seria realizada, autorização do Departamento de Assuntos Acadêmicos (DAA) para a utilização das notas, Termo de Consentimento Livre e Esclarecido (TCLE), entre outros) foram submetidos por meio da Plataforma Brasil. Este trabalho foi aprovado em sua primeira versão e teve seu parecer final $\mathrm{n}^{\circ}$ 3.092.395.

\subsection{Caracterização da Pesquisa e Aspectos Metodológicos}

Quanto aos objetivos, esta pesquisa é caracterizada como descritiva e, no que diz respeito aos procedimentos, é definida como survey. Os dados foram coletados por meio da aplicação de questionário de pesquisa presencialmente com os alunos do curso de Ciências Contábeis de uma IES paranaense.

Para a coleta de dados, foram utilizados dois questionários de pesquisa. $\mathrm{O}$ primeiro instrumento é o KLSI v. 3.1 administrado pelo Hay Group®. A empresa detém os direitos de uso do instrumento e, para obtê-lo para fins deste estudo, foi realizado um contato com o Hay Group® por e-mail. Após o preenchimento dos formulários requeridos pela organização, como informações sobre a pesquisa e envio do currículo, a investigação foi aprovada pela comissão e os responsáveis enviaram o instrumento traduzido e revisado em língua portuguesa.

É um instrumento que descreve o modo como o indivíduo aprende e lida com as circunstâncias do dia a dia, sendo composto por 12 frases com uma escolha de finais, ou seja, o respondente classifica os finais para cada uma das sentenças, conforme corresponda melhor ao modo de aprendizagem. A partir de situações recentes em que o entrevistado teve que aprender algo novo, ele realiza a classificação de "4", para o término da sentença que descreve como ele 
aprende melhor, até "1", para o final da sentença que parece menos com a maneira de aprendizagem. Após a classificação, o respondente preenche os valores que atribuiu em cada uma das sentenças e os soma.

Portanto, conforme exposto no "Referencial Teórico", em "Estilos de Aprendizagem", além de permitir a identificação entre ser concreto ou abstrato e entre ser ativo ou reflexivo, este instrumento possibilita a identificação dos estilos de aprendizagem individuais (divergente, acomodador, assimilador e convergente) por meio do gráfico que apresenta o ciclo de aprendizagem experiencial (Figura 1) (Kolb \& Kolb 2008; McCarthy, 2010).

O segundo questionário, adaptado do estudo de Amaro (2014), traz cinco questões em Escala Likert com intervalo de 11 pontos (nota de 0 a 10), e cada uma representa um fator analisado: ambiente interno; estrutura; sistema técnico; estratégia do PPC; e estratégia do corpo docente. Além disso, também constam mais duas questões, uma para a dedicação no curso e outra para a autoavaliação (desempenho), bem como questões que dizem respeito à caracterização do respondente. É importante ressaltar que, para o desempenho do aluno, foram utilizadas as notas fornecidas pela universidade.

Com o intuito de analisar o tempo médio para responder o questionário, realizar alterações e melhorar a linguagem das questões, foi feito um pré-teste com 13 voluntários, que são discentes do $2^{\circ}, 3^{\circ}$ e $4^{\circ}$ anos do curso de Graduação em Ciências Contábeis, mas que não participaram da amostra final da pesquisa. Os alunos responderam ao questionário em um tempo médio de 15 minutos. Durante a aplicação, os discentes deram sugestões quanto à linguagem utilizada no bloco de estilos de aprendizagem, recomendando colocar um texto explicativo menos formal para melhorar o entendimento. Na questão sobre "experiência na área", sugeriram que aumentasse uma alternativa para quem tivesse menos de um ano de experiência e, na questão sobre "jornada de trabalho", sugeriram alterar "trabalho eventualmente" para "trabalho às vezes".

Com os dados do pré-teste coletados, foi realizado o teste de confiabilidade (Alfa de Cronbach) nas questões de Escala Likert, por meio do software Stata MP-64. Esse teste varia de 0 a 1 , sendo os valores acima de 0,70 considerados aceitáveis (Hair, Black, Babin, Anderson, \& Tatham, 2005). O valor apurado para o Alfa de Cronbach foi de 0,9081, acima do parâmetro exigido, reforçando a confiabilidade do instrumento da pesquisa.

Após o pré-teste, os questionários foram aplicados aos alunos do $2^{\circ}, 3^{\circ}$ e $4^{\circ}$ anos, considerando que são os que cursaram as disciplinas que representam os maiores índices de reprovação, sendo elas: Laboratório Contábil; Contabilidade e Análise de Custos; Contabilidade e Orçamento Governamental I; Contabilidade Geral I; Contabilidade Geral II; Elaboração das Demonstrações Contábeis; e Iniciação à Pesquisa em Contabilidade. Foram obtidas 229 respostas válidas.

Para obter as notas dos discentes, foi necessário um pedido junto à DAA, o qual foi realizado pessoalmente pelas pesquisadoras por meio de uma solicitação por escrito e com anexo do parecer de aprovação pelo Comitê de Ética e Pesquisa (CEP). Após a aprovação da diretora, foi realizada uma reunião junto aos responsáveis do Núcleo de Processamento de Dados (NPD) da IES, para responder as dúvidas referentes à coleta e à pesquisa. Por fim, os dados com as notas dos discentes foram recebidos via e-mail.

Os dados obtidos foram digitados em planilha Excel ${ }^{\circledR}$ e analisados estatisticamente com o auxílio do software Statistica versão 13.2 single user e Stata MP-64. Inicialmente, foi realizado o teste de confiabilidade (Alfa de Cronbach) nas questões de Escala Likert para cada câmpus (a IES atua em dois câmpus, I e II). Esse teste varia de 0 a 1 , sendo os valores de acima de 0,70 considerados aceitáveis (Hair et al., 2005). O valor apurado para o Alfa de Cronbach nas questões do banco de dados do Câmpus I foi de 0,9105 e, nas do Câmpus II, foi de 0,9004, ambos acima do parâmetro exigido.

A estatística descritiva foi utilizada para realização da descrição de um conjunto de dados populacional (Triola, 2012). A partir disso, inicialmente, foram calculadas as medidas descritivas: média; desvio padrão para as variáveis quantitativas (idade e ano do curso); e tabelas de frequência 
simples e de dupla entrada para as variáveis qualitativas (gênero, estado civil, jornada de trabalho, escola do ensino médio etc.).

Nas questões em Escala Likert (fatores institucionais), para testar a validade dos construtos, foi realizada uma análise fatorial confirmatória. Os fatores que apresentaram um coeficiente superior a 0,5 apresentaram validade convergente, enquanto os que apresentaram um coeficiente inferior foram excluídos e analisados de forma isolada. Além disso, para analisar a significância das cargas fatoriais, foi feito o comando para ajuste de equação do modelo e, a partir disso, foi realizado o teste de confiabilidade em cada construto da pesquisa, sendo os valores acima de 0,70 considerados aceitáveis.

Na disciplina de Contabilidade Geral I, apenas os fatores "estrutura", "PPC" e "estratégia do corpo docente", passaram pelo modelo de regressão, pois apresentaram índices de confiabilidade acima de 0,70 . Os demais itens foram adicionados no modelo de forma isolada. Nas disciplinas de Contabilidade Geral II, Iniciação à Pesquisa em Contabilidade, Laboratório Contábil, Contabilidade Pública e Orçamento Governamental I e Contabilidade e Análise de Custos, os fatores "estrutura", "sistema técnico (PPC)" e "estratégia do corpo docente" apresentaram índices de confiabilidade acima de 0,70. Apenas na disciplina de Elaboração das Demonstrações Contábeis, todos os fatores (ambiente interno, estrutura, sistema técnico, estratégia do corpo docente e PPC) apresentaram índices de confiabilidade acima de 0,70.

Após realizar a análise fatorial confirmatória, a identificação da significância e a confiabilidade de cada construto, as variáveis quantitativas foram transformadas em variáveis dummy, para, assim, serem agrupadas dentro do modelo de regressão. O primeiro modelo de regressão foi composto por todas as variáveis explicativas (fatores institucionais, fatores pessoais e estilos de aprendizagem), para verificar suas possíveis relações sobre a variável dependente (nota final na disciplina). Entretanto, cada modelo de regressão foi refinado e ajustado.

Para realizar o refinamento de cada modelo de regressão (um para cada disciplina), foi observado, por meio do primeiro modelo de regressão, quais as variáveis que se apresentavam como menos significativas ( $\mathrm{p}>10 \%$ ), sendo estas excluídas de forma gradativa, pois o que antes poderia parecer como menos significativa com a exclusão de uma variante, pode vir a ser significativa nesta etapa.

Considerando que o estudo aborda a influência de fatores pessoais, institucionais e dos estilos de aprendizagem no desempenho dos alunos, foram definidas as seguintes variáveis (dependente e independente):

- Dependente (y): desempenho dos alunos, mensurados a partir da nota das disciplinas que possuem o maior índice de reprovação;

- Independente (x): fatores pessoais, que são as características dos alunos (forma de ingresso, turno, ano do curso, escola do ensino médio, estado civil, experiência na área, horas de estudo extraclasse, gênero, idade, jornada de trabalho, membros da família, moradia, nível de instrução do responsável, participação econômica familiar e renda familiar);

- Independente (x): fatores institucionais, que são os referentes à instituição de ensino (estrutura, sistema técnico, estratégia do curso (PPC) e estratégia do curso (corpo docente)); e

- Independente (x): estilos de aprendizagem dos discentes, os quais foram identificados a partir do LSI Versão 3.1, de David A. Kolb.

A Tabela 3 apresenta as hipóteses testadas, resgatadas do referencial teórico e a relação esperada sobre o desempenho dos estudantes. 
Tabela 3

Hipóteses testadas

\begin{tabular}{|c|c|c|}
\hline & Hipóteses & $\begin{array}{c}\text { Relação } \\
\text { esperada }\end{array}$ \\
\hline H1 & $\begin{array}{l}\text { Existem diferenças estatisticamente significativas entre o desempenho dos alunos } \\
\text { e fatores pessoais na instituição de ensino. }\end{array}$ & \multirow{8}{*}{$+/-$} \\
\hline H1a & $\begin{array}{l}\text { Existem diferenças estatisticamente significativas entre o desempenho dos alunos } \\
\text { e a forma de ingresso na instituição. }\end{array}$ & \\
\hline H1b & $\begin{array}{l}\text { Existem diferenças estatisticamente significativas entre o desempenho dos alunos } \\
\text { e o turno e a escola frequentados durante o ensino médio. }\end{array}$ & \\
\hline H1c & $\begin{array}{l}\text { Existem diferenças estatisticamente significativas entre o desempenho dos alunos } \\
\text { e a experiência na área e a jornada de trabalho. }\end{array}$ & \\
\hline H1d & $\begin{array}{l}\text { Existem diferenças significativas no rendimento acadêmico de acordo com as horas } \\
\text { de estudo extraclasse. }\end{array}$ & \\
\hline H1e & $\begin{array}{l}\text { Existem diferenças significativas no rendimento acadêmico de acordo com o } \\
\text { gênero, a faixa etária o estado civil dos alunos. }\end{array}$ & \\
\hline H1f & $\begin{array}{l}\text { Existem diferenças significativas no rendimento acadêmico de acordo com a } \\
\text { quantidade de membros da família e com o nível de instrução do responsável. }\end{array}$ & \\
\hline H1g & $\begin{array}{l}\text { Existem diferenças significativas no rendimento acadêmico conforme a } \\
\text { participação econômica familiar e a renda familiar. }\end{array}$ & \\
\hline $\mathbf{H} 2$ & $\begin{array}{l}\text { Há influência estatisticamente positiva e significativa do fator "ambiente interno" } \\
\text { no desempenho dos alunos. }\end{array}$ & $+/-$ \\
\hline $\mathbf{H 3}$ & $\begin{array}{l}\text { Há influência estatisticamente positiva e significativa do fator "estrutura" no } \\
\text { desempenho dos alunos. }\end{array}$ & - \\
\hline H4 & $\begin{array}{l}\text { Há influência estatisticamente positiva e significativa do fator "sistema técnico" } \\
\text { no desempenho dos alunos. }\end{array}$ & + \\
\hline H5 & $\begin{array}{l}\text { Há influência estatisticamente positiva e significativa do fator "PPC" no } \\
\text { desempenho dos alunos. }\end{array}$ & + \\
\hline H6 & $\begin{array}{l}\text { Há influência estatisticamente positiva e significativa do fator "estratégia do } \\
\text { corpo docente" no desempenho dos alunos. }\end{array}$ & $+/-$ \\
\hline H7 & $\begin{array}{l}\text { Há influência estatisticamente positiva e significativa dos estilos de aprendizagem } \\
\text { no desempenho dos alunos. }\end{array}$ & + \\
\hline
\end{tabular}

Fonte: elaborado pelas autoras.

\section{ANÁLISE E DISCUSSÃO DOS RESULTADOS}

\subsection{Análise Descritiva}

A primeira parte do estudo diz respeito à caracterização dos respondentes. Dos 229 alunos participantes da pesquisa, 105 são do $2^{\circ}$ ano, 62 do $3^{\circ}$ ano, e 62 do $4^{\circ}$ ano da Graduação. São três as formas de Ingresso na IES: (i) realizando o vestibular e concorrendo a uma das vagas universais; (ii) por meio de vaga reservada para as cotas sociais; e (iii) pelo PAS, processo pelo qual o aluno faz uma prova no fim do $1^{\circ}, 2^{\circ}$ e $3^{\circ}$ anos do ensino médio. Dos 229 alunos, 68,6\% $(\mathrm{n}=157)$ ingressaram por meio das vagas universais, $21 \%(\mathrm{n}=48)$ entraram pelo PAS e os demais, $10,5 \%$ $(\mathrm{n}=24)$ dos alunos, foram aprovados por meio das cotas sociais.

Quanto ao gênero, 58\% ( $n=133)$ são do gênero feminino e $42 \%(n=96)$, do masculino. Em relação à faixa etária dos respondentes, o perfil que apresentou predominância foi o de idade entre 18 e 23 anos, aproximadamente $78 \%(\mathrm{n}=179)$ da amostra total, enquanto apenas $6,1 \%$ $(n=14)$ correspondem aos alunos que têm mais de 30 anos. Em relação à formação de ensino médio, os alunos, em sua maioria, tiveram a formação em escola pública 73,4\% ( $\mathrm{n}=168), 21,8 \%$ $(n=50)$ estudaram em escola particular, enquanto os demais, $4,8 \%(n=11)$, fizeram uma parte em escola pública e outra em escola particular. 
Dos 229 alunos, 47,2\% ( $\mathrm{n}=108)$ trabalham em tempo integral (44 horas semanais). Para as horas extraclasse, $38,9 \%(n=89)$ e $32,5 \%(n=75)$ responderam dedicar-se de 1 a 2 horas e 3 a 5 , respectivamente. A maioria dos discentes $46,3 \%(\mathrm{n}=106)$ respondeu que mora com até quatro pessoas e $55,5 \%(\mathrm{n}=127)$ residem em residência própria e quitada. Quanto à experiência, 37,6\% $(n=86)$ dos respondentes não possuem experiência na área de Contabilidade.

$\mathrm{O}$ item a seguir apresenta uma análise das preferências de aprendizagem identificadas.

\subsection{Dimensões de Aprendizagem}

Os pesos atribuídos pelos alunos nas alternativas encontradas no IEA são somados e representam quatro índices: EC; OR; CA; e EA. As preferências de aprendizagem são indicadas a partir da combinação dos escores CA $\times$ EC e EA $\times$ OR, resultando em duas dimensões da aprendizagem, que indicarão se o aluno possui o estilo convergente, divergente, assimilador ou acomodador.

Após analisar a frequência em cada fase do ciclo de aprendizagem, notou-se que, para os alunos do Câmpus I, não existe uma diferença ampla entre os modos de captação de experiência de CA (pensando) e de EC (experimentando), visto que 58\% $(\mathrm{n}=45)$ aprendem pensando e os demais, $42 \%(\mathrm{n}=33)$, experimentando. Para o Câmpus II, essa diferença foi maior, já que houve a predominância do modo de aprendizagem de CA para $81 \%(\mathrm{n}=123)$ dos alunos, enquanto apenas $19 \%(\mathrm{n}=28)$ demonstraram que tendem a captar as informações pela EC.

Outra frequência observada é a dimensão da transformação da experiência, que é caracterizada pela observação reflexiva (observando) e experimentação ativa (fazendo). Tanto no Câmpus I quanto no Câmpus II, houve a predominância da observação reflexiva, o que demonstra que a maioria observa antes de fazer um juízo, ou seja, em situação de aprendizagem, o estudante tende a ser paciente e objetivo (Cerqueira, 2000; Kolb \& Kolb, 1984). E, em ambiente de aprendizagem, ele prefere discutir o conteúdo, perguntas que gerem reflexão e questões retóricas (Svinicki \& Dixon, 1987).

Similar aos achados deste estudo, Nogueira (2009) também encontrou a predominância da observação reflexiva (78\% dos casos) ao analisar a dimensão da transformação em sua amostra.

Por mais que a aprendizagem seja formada pelas quatros habilidades, devido às experiências de vida, demanda ambiental e genética, os indivíduos desenvolvem uma maneira dominante em cada uma das dimensões e, ao utilizar certas habilidades mais que as outras, determinam o estilo de aprendizagem (Kolb \& Kolb, 2008; Leitão, 2006). Sendo assim, discorrese a seguir a respeito da identificação dos estilos de aprendizagem dos alunos que compõem a amostra da pesquisa.

\subsection{Estilos de Aprendizagem}

Depois de identificadas as dimensões de $\mathrm{CA} \times \mathrm{EC}$ e de $\mathrm{EA} \times \mathrm{OR}$, foi possível a identificação (por meio do gráfico de determinação do estilo de aprendizagem) do estilo de aprendizagem assimilador em ambos os câmpus. Em segundo lugar, o estilo identificado com maior frequência foi o divergente. Porém, no Câmpus II, essa diferença foi pequena, podendo-se considerar que os alunos desse câmpus tendem a ser assimiladores e divergentes. $\mathrm{O}$ estilo acomodador é o que ocorre em menor frequência (32 alunos) dentre os 229 alunos da amostra.

Embora Kolb e Kolb (2008) tenham apresentado alguns estudos, como o de Clarke (1977), Jervis (1983), Rowe e Waters (1992) e Loo (2002), que concluíram que os contadores tendem a ser convergentes, os resultados encontrados nesta pesquisa foram diferentes, porém estão em consonância com o estudo de Cerqueira (2000), no qual a autora identificou a predominância do estilo assimilador nos alunos da área de Ciências Sociais Aplicadas. Também os estudos de Nogueira (2009) e Hamann (2011) identificaram o estilo de aprendizagem assimilador predominante entre os alunos de Contabilidade, e o acomodador em menor frequência.

A predominância do estilo assimilador, tanto para esta pesquisa quanto para as citadas anteriormente, pode ser decorrente da faixa etária dos respondentes (predominantemente da 
geração z, de nativos digitais), pelas características de menos focados em pessoas e mais voltados para ideias. Enquanto os estudos mais antigos (predominantemente da Geração X) apresentaram o perfil convergente "mais focados em testar teorias".

Da mesma forma, Santos et al. (2014) observaram que o perfil assimilador é dominante entre alunos de Contabilidade na Graduação, na Especialização e também no Mestrado, assim como Yanardöner et al. (2014) identificaram este perfil nos alunos da Universidade de Istambul.

Porém na análise da Disciplina Laboratório Contábil, os discentes do estilo convergente obtiveram as melhores médias. Também o estudo de Lizote, Alves, Teston e Olm (2019), que utilizou tanto o método VARK quanto o Kolb para identificar como os discentes concentram, absorvem e transformam as informações recebidas em conhecimento, em 257 estudantes do curso de Ciências Contábeis de uma universidade comunitária do Sul do Brasil, obteve-se a predominância do estilo convergente $(43,6 \%)$, seguido do assimilador $(40,1 \%)$, enquanto o divergente foi o menos representativo na amostra.

Ao analisar os dois estilos de aprendizagem predominantes na amostra, assimilador e divergente, em conjunto, eles representam $67 \%$ dos alunos. Conforme recomendam Polat et al. (2015), os professores devem ser informados quanto aos estilos de aprendizagem, para, assim, realizarem uma organização no ambiente educacional, a fim de determinar métodos de ensino, abordagens e materiais, para que os alunos possam aproveitar melhor o conteúdo exposto e aumentar o nível de aprendizagem.

Os assimiladores são menos focados em pessoas e mais voltados para ideias, preferem palestras, gostam de leituras e principalmente pensar sobre coisas e modelos analíticos (Kolb, 1984; Kolb \& Kolb, 2005). São melhores em compreender muitas informações e colocá-las de modo conciso e lógico, sendo mais interessante, para eles, o significado lógico de uma teoria do que sua aplicação na prática (Kolb, 1984; Cerqueira, 2000; Kolb \& Kolb, 2005). Quanto aos divergentes, uma de suas características predominantes é a capacidade imaginativa, geração de ideias (Kolb \& Kolb, 2005). Além disso, gostam de coletar informações, gostam de trabalhar em grupo e de se envolver com pessoas, ou seja, não apreciam os estudos individuais (Kolb, 1984; Cerqueira, 2000; Kolb \& Kolb, 2005).

Os professores, ao preparar suas aulas e técnicas de ensino, devem considerar os vários estilos de aprendizagem e as características diferentes dos estudantes (Yanardöner et al., 2014). Entretanto, considerando que, nesta amostra, os alunos tendem a ser assimiladores e divergentes, sugere-se que os profissionais do ensino trabalhem com textos que gerem reflexões sobre o assunto abordado e estimulem discussões em grupo (Nogueira, 2009).

\subsection{Interpretação dos Resultados}

Após refinar o modelo de regressão (Tabela 4) em cada uma das disciplinas, considerando um nível de significância de 5\% (p < 0,05) e, em alguns casos, de 10\% (p < 0,10), por meio da Tabela 5, é possível observar as disciplinas analisadas, o número de respondentes de cada disciplina e um resumo dos resultados e relações encontradas.

\section{Tabela 4}

Modelo de regressão das disciplinas

\begin{tabular}{|c|c|c|c|c|c|c|}
\hline \multicolumn{7}{|c|}{ Iniciação à Pesquisa em Contabilidade } \\
\hline \multirow{3}{*}{$\begin{array}{c}\mathrm{N}=201 \\
\text { Nota na disciplina } \\
\text { Modernidade dos } \\
\text { laboratórios de } \\
\text { informática }\end{array}$} & \multirow{3}{*}{$\begin{array}{c}\frac{F(8,192)=6.33}{\text { Coef. }} \\
0.1460461\end{array}$} & \multirow{3}{*}{$\begin{array}{c}\text { Prob }>F=0 \\
\text { Std. Err. } \\
0.0541096\end{array}$} & \multicolumn{2}{|c|}{$\mathrm{R}^{2}=0.2088$} & \multirow{2}{*}{\multicolumn{2}{|c|}{$\begin{array}{c}\text { Adj } \mathrm{R}^{2}=0.1759 \\
{[95 \% \text { Conf. Interval }]}\end{array}$}} \\
\hline & & & $\mathrm{T}$ & $\mathrm{P}$ & & \\
\hline & & & 2.7 & $0.008 *$ & 0.0393206 & 0.252772 \\
\hline Estado civil (outros) & -3.183896 & 0.8084596 & -3.94 & $0.000 *$ & -4.778499 & -1.58929 \\
\hline $\begin{array}{c}\text { Faixa etária (18 a } 23 \\
\text { anos) }\end{array}$ & 0.9473494 & 0.3632748 & 2.61 & $0.010^{*}$ & 0.2308274 & 1.663871 \\
\hline
\end{tabular}




\begin{tabular}{|c|c|c|c|c|c|c|}
\hline $\begin{array}{c}\text { Horas extraclasse ( } 1 \text { a } 2 \\
\text { horas) }\end{array}$ & 0.9633127 & 0.3397964 & 2.83 & $0.005^{*}$ & 0.2930994 & 1.633526 \\
\hline $\begin{array}{c}\text { Horas extraclasse (3 a } 5 \\
\text { horas) }\end{array}$ & 1.123278 & 0.3479033 & 3.23 & $0.001 *$ & 0.4370746 & 1.809481 \\
\hline $\begin{array}{c}\text { Horas extraclasse (9 a } 10 \\
\text { horas) }\end{array}$ & 1.168487 & 0.6650796 & 1.76 & $0.081 * *$ & -0.1433139 & 2.480288 \\
\hline $\begin{array}{c}\text { Participação econômica } \\
\text { familiar (trabalho e } \\
\text { contribuo) }\end{array}$ & -0.6735983 & 0.2813676 & -2.39 & $0.018 *$ & -1.228567 & -0.11863 \\
\hline $\begin{array}{c}\text { Experiência na área (7 a } \\
12 \text { meses) }\end{array}$ & -0.8594588 & 0.3311054 & -2.6 & $0.010^{*}$ & -1.51253 & -0.20639 \\
\hline _cons & 5.139563 & 0.4886866 & 10.52 & 0.000 & 4.17568 & 6.103447 \\
\hline \multicolumn{7}{|c|}{ Laboratório Contábil } \\
\hline $\mathrm{N}=119$ & $F(10,108)=4.20$ & Prob $>F=0$ & \multicolumn{2}{|c|}{$\mathrm{R}^{2}=0.2799$} & \multirow{2}{*}{\multicolumn{2}{|c|}{$\begin{array}{l}\text { Adj } R^{2}=0.2132 \\
{[95 \% \text { Conf. Interval }]}\end{array}$}} \\
\hline Nota na disciplina & Coef. & Std. Err. & $\mathrm{T}$ & $\mathrm{P}$ & & \\
\hline $\begin{array}{c}\text { Faixa etária (18 a } 23 \\
\text { anos) }\end{array}$ & 1.157909 & 0.4558853 & 2.54 & $0.013 *$ & 0.2542653 & 2.061553 \\
\hline $\begin{array}{l}\text { Membros da família } \\
\text { (até dois) }\end{array}$ & 2.036629 & 0.8382225 & 2.43 & $0.017 *$ & 0.3751267 & 3.698132 \\
\hline $\begin{array}{l}\text { Membros da família } \\
\text { (até quatro) }\end{array}$ & 1.8066 & 0.8265075 & 2.19 & $0.031 *$ & 0.1683183 & 3.444881 \\
\hline $\begin{array}{c}\text { Membros da família } \\
\text { (até seis) }\end{array}$ & 2.190009 & 1.140087 & 1.92 & $0.057 *$ & -0.0698406 & 4.444881 \\
\hline $\begin{array}{l}\text { Membros da família } \\
\text { (nenhum) }\end{array}$ & 3.228369 & 1.080262 & 2.99 & $0.003 *$ & 1.087101 & 5.369636 \\
\hline $\begin{array}{l}\text { Horas extraclasse (1 a } \\
\text { 2) }\end{array}$ & 1.380867 & 0.5110409 & 2.70 & $0.008^{*}$ & 0.3678949 & 2.393838 \\
\hline $\begin{array}{l}\text { Horas extraclasse ( } 3 \mathrm{a} \\
5)\end{array}$ & 1.557555 & 0.5563431 & 2.80 & $0.006^{*}$ & 0.4547867 & 2.660324 \\
\hline $\begin{array}{c}\text { Horas extraclasse (9 a } \\
10)\end{array}$ & 2.099085 & 0.9059322 & 2.32 & $0.022 *$ & 0.3033698 & 3.894799 \\
\hline Turno (matutino) & -0.9975016 & 0.416582 & -2.39 & $0.018^{*}$ & -1.823239 & -0.1717637 \\
\hline $\begin{array}{c}\text { Estilos de } \\
\text { aprendizagem } \\
\text { (convergente) }\end{array}$ & 1.272771 & 0.4877795 & 2.61 & $0.010^{*}$ & 0.3059077 & 2.239635 \\
\hline _cons & 2.495575 & 1.054162 & 2.37 & 0.020 & 0.4060442 & 4.585106 \\
\hline \multicolumn{7}{|c|}{ Contabilidade Geral I } \\
\hline $\mathrm{N}=207$ & $\mathrm{~F}(13,193)=5.02$ & Prob $>F=0$ & \multicolumn{2}{|c|}{$\mathrm{R}^{2}=0.2528$} & \multicolumn{2}{|c|}{$\operatorname{Adj} R^{2}=0.2025$} \\
\hline Nota na disciplina & Coef. & Std. Err. & $\mathrm{T}$ & $\mathrm{P}$ & \multicolumn{2}{|c|}{ [95\% Conf. Interval] } \\
\hline Coordenador do curso & 0.1848595 & 0.0604471 & 3.06 & $0.003 *$ & 0.0656377 & 0.3040813 \\
\hline Estado civil (outros) & 2.79434 & 1.048035 & 2.67 & $0.008^{*}$ & 0.7272676 & 4.861412 \\
\hline $\begin{array}{c}\text { Faixa etária (30 anos ou } \\
\text { mais) }\end{array}$ & -2.017084 & 0.6396958 & -3.15 & $0.002 *$ & -3.278776 & -0.7553915 \\
\hline $\begin{array}{l}\text { Trabalham entre } 20 \text { e } 44 \\
\text { horas }\end{array}$ & 1.275661 & 0.4788487 & 2.66 & $0.008 *$ & 0.3312123 & 2.220109 \\
\hline Trabalham até 20 horas & 0.6467535 & 0.3052339 & 2.12 & $0.035^{*}$ & 0.0447309 & 1.248776 \\
\hline Não trabalham & 2.652982 & 1.197011 & 2.22 & $0.028 *$ & 0.2920785 & 5.013885 \\
\hline $\begin{array}{c}\text { Ensino médio (maior } \\
\text { parte em escola } \\
\text { particular) }\end{array}$ & -1.925024 & 0.849037 & -2.27 & $0.024 *$ & -3.599606 & -0.2504412 \\
\hline $\begin{array}{c}\text { Ensino médio (todo em } \\
\text { escola particular) }\end{array}$ & -0.6519375 & 0.331003 & -1.97 & $0.050^{*}$ & -1.304785 & 0.0009103 \\
\hline $\begin{array}{c}\text { Membros da família } \\
\text { (outras pessoas) }\end{array}$ & 0.9605503 & 0.2706431 & 3.55 & $0.000^{*}$ & 0.4267524 & 1.494348 \\
\hline $\begin{array}{c}\text { Horas extraclasse (1 a } 2 \\
\text { horas) }\end{array}$ & 1.060203 & 0.332818 & 3.19 & $0.002 *$ & 0.4037754 & 1.71663 \\
\hline
\end{tabular}




\begin{tabular}{|c|c|c|c|c|c|c|}
\hline $\begin{array}{c}\text { Horas extraclasse ( } 3 \text { a } 5 \\
\text { horas) }\end{array}$ & 0.7522331 & 0.3407032 & 2.21 & $0.028 *$ & 0.0802534 & 1.424213 \\
\hline $\begin{array}{l}\text { Horas extraclasse (mais } \\
\text { de 10) }\end{array}$ & 1.972733 & 0.8891512 & 2.22 & $0.028^{*}$ & 0.2190318 & 3.726434 \\
\hline $\begin{array}{l}\text { Participação econômica } \\
\text { na família (não } \\
\text { trabalha) }\end{array}$ & -3.044286 & 1.128275 & -2.70 & $0.008 *-$ & -5.269617 & -0.8189539 \\
\hline _cons & 4.408631 & 0.5469941 & 8.06 & 0.000 & 3.329778 & 5.487485 \\
\hline \multicolumn{7}{|c|}{ Contabilidade Geral II } \\
\hline $\mathrm{N}=205$ & $\mathrm{~F}(8,196)=6.01$ & \multicolumn{2}{|c|}{ Prob $>F=0$} & $=0.1970$ & \multicolumn{2}{|c|}{$\operatorname{Adj} R^{2}=0.1642$} \\
\hline Nota na disciplina & Coef. & Std. Err. & $\mathrm{T}$ & $\mathrm{P}$ & \multicolumn{2}{|c|}{ [95\% Conf. Interval] } \\
\hline Estado civil (divorciado) & -3.695815 & 0.9549331 & -3.87 & $0.000^{*}$ & -5.579078 & -1.812552 \\
\hline Faixa etária (18 a 23 anos) & 0.9490084 & 0.3780129 & 2.51 & $0.013^{*}$ & 0.2035135 & 1.694503 \\
\hline $\begin{array}{c}\text { Horas extraclasse (1 a } 2 \\
\text { horas) }\end{array}$ & 1.116422 & 0.4231323 & 2.64 & $0.009 *$ & 0.2819449 & 1.950898 \\
\hline $\begin{array}{c}\text { Horas extraclasse (3 a } 5 \\
\text { horas) }\end{array}$ & 0.9631416 & 0.4243381 & 2.27 & $0.024^{*}$ & 0.1262869 & 1.799996 \\
\hline $\begin{array}{c}\text { Horas extraclasse (6 a } 9 \\
\text { horas) }\end{array}$ & 1.467306 & 0.563508 & 2.60 & $0.010^{*}$ & 0.3559883 & 2.578623 \\
\hline $\begin{array}{l}\text { Horas extraclasse (9 a } 10 \\
\text { horas) }\end{array}$ & 2.001989 & 0.6758087 & 2.96 & $0.003 *$ & 0.6691987 & 3.334779 \\
\hline $\begin{array}{l}\text { Horas extraclasse (mais de } \\
10 \text { ) }\end{array}$ & 1.76612 & 0.9411994 & 1.88 & $0.062 * *$ & -0.090058 & 3.622298 \\
\hline Turno (matutino) & -1.552596 & 0.4380105 & -3.54 & $0.000 *$ & -2.416414 & -0.6887773 \\
\hline cons & 5.494277 & 0.5183803 & 10.60 & 0.0000 & 4.471958 & 6.516596 \\
\hline \multicolumn{7}{|c|}{ Elaboração das Demonstrações Contábeis } \\
\hline $\mathrm{N}=137$ & $(7,129)=13.44$ & Prob $>F=0$ & \multicolumn{2}{|c|}{$\mathrm{R}^{2}=0.4218$} & \multirow{2}{*}{\multicolumn{2}{|c|}{$\frac{\text { Adj } \mathrm{R}^{2}=0.3904}{[95 \% \text { Conf. Interval] }}$}} \\
\hline Nota na disciplina & Coef. & Std. Err. & $\mathrm{T}$ & $\mathrm{P}$ & & \\
\hline $\begin{array}{l}\text { Estado civil } \\
\text { (divorciado) }\end{array}$ & -6.811812 & 1.443535 & -5.14 & $0.000 *$ & -9.667881 & -3.955744 \\
\hline $\begin{array}{c}\text { Faixa etária (30 anos } \\
\text { ou mais) }\end{array}$ & -2.351504 & 0.613638 & -3.77 & $0.000^{*}$ & -3.565602 & -1.137407 \\
\hline $\begin{array}{c}\text { Faixa etária (18 a } 23 \\
\text { anos) }\end{array}$ & 0.5771031 & 0.3284244 & 2.03 & $0.081 * *$ & -0.072693 & 1.226899 \\
\hline $\begin{array}{l}\text { Membros da família } \\
\text { (mais de seis) }\end{array}$ & -1.307851 & 0.7369242 & -1.67 & $0.078 * *$ & -2.765874 & 0.1501712 \\
\hline $\begin{array}{c}\text { Horas extraclasse } \\
(\text { mais de } 10)\end{array}$ & 2.125389 & 1.031725 & 1.87 & $0.041 *$ & 0.0840949 & 4.166682 \\
\hline Moradia (alugada) & -0.8406243 & 0.3773876 & -2.45 & $0.028 *$ & -1.587295 & -0.0939537 \\
\hline Turno (matutino) & 1.227152 & 0.2727392 & 3.77 & $0.000 *$ & 0.6875305 & 1.766773 \\
\hline cons & 6.811812 & 0.3274054 & 18.92 & 0.000 & 6.164032 & 7.459592 \\
\hline \multicolumn{7}{|c|}{ Contabilidade e Análise de Custos } \\
\hline $\mathrm{N}=214$ & $\mathrm{~F}(11,202)=7.15$ & Prob $>F=0$ & \multicolumn{2}{|c|}{$\mathrm{R}^{2}=0.2803$} & \multicolumn{2}{|c|}{$\operatorname{Adj} R^{2}=0.2411$} \\
\hline Nota na disciplina & Coef. & Std. Err. & $\mathrm{T}$ & $\mathrm{P}$ & \multicolumn{2}{|c|}{ [95\% Conf. Interval] } \\
\hline $\begin{array}{c}\text { Projeto Pedagógico do } \\
\text { Curso (PPC) }\end{array}$ & 0.1569003 & 0.0843458 & 1.86 & $0.064 * *$ & -0.0094109 & $9 \quad 0.3232114$ \\
\hline Estado civil (casado) & 0.9489049 & 0.4910489 & 1.93 & $0.055^{*}$ & -0.0193342 & 1.917144 \\
\hline Trabalha até 20 horas & 1.006346 & 0.4396003 & 2.29 & $0.023 *$ & 0.1395518 & 1.87314 \\
\hline $\begin{array}{c}\text { Membros da família (mais } \\
\text { de seis) }\end{array}$ & -3.605915 & 1.970406 & -1.83 & $0.069 * *$ & -7.491117 & 0.2792872 \\
\hline $\begin{array}{c}\text { Horas extraclasse (1 a } 2 \\
\text { horas) }\end{array}$ & 3.097234 & 0.4539814 & 6.82 & $0.000 *$ & 2.202084 & 3.992384 \\
\hline $\begin{array}{c}\text { Horas extraclasse (3 a } 5 \\
\text { horas) }\end{array}$ & 3.084516 & 0.4615169 & 6.68 & $0.000 *$ & 2.174508 & 3.994525 \\
\hline $\begin{array}{c}\text { Horas extraclasse (6 a } 9 \\
\text { horas) }\end{array}$ & 2.940108 & 0.6175343 & 4.76 & $0.000 *$ & 1.722467 & 4.157748 \\
\hline
\end{tabular}




\begin{tabular}{|c|c|c|c|c|c|c|}
\hline $\begin{array}{c}\text { Horas extraclasse (9 a } 10 \\
\text { horas) }\end{array}$ & 3.380192 & 0.7992022 & 4.23 & $0.000 *$ & 1.804343 & 4.956041 \\
\hline $\begin{array}{l}\text { Horas extraclasse (mais de } \\
10 \text { ) }\end{array}$ & 4.355798 & 0.8827046 & 4.93 & $0.000 *$ & 2.6153302 & 6.096295 \\
\hline $\begin{array}{l}\text { Renda familiar (11 salários } \\
\text { mínimos ou mais) }\end{array}$ & 3.496865 & 0.9541571 & 3.66 & $0.000 *$ & 1.61548 & 5.37825 \\
\hline $\begin{array}{c}\text { Renda familiar (4 a } 5 \\
\text { salários mínimos) }\end{array}$ & 0.7099703 & 0.3014059 & 2.36 & $0.019 *$ & 0.115665 & 1.304276 \\
\hline _cons & 3.39504 & 0.4157339 & 8.17 & 0.000 & 2.575306 & 4.214775 \\
\hline \multicolumn{7}{|c|}{ Contabilidade Pública e Orçamento Governamental I } \\
\hline $\mathrm{N}=224$ & $F(10,213)=7.01$ & Prob $>F=0$ & \multicolumn{2}{|c|}{$\operatorname{Adj~R} R^{2}=0.2476$} & \multicolumn{2}{|c|}{$\operatorname{Adj} R^{2}=0.2122$} \\
\hline Nota na disciplina & Coef. & Std. Err. & $\mathrm{T}$ & $\mathrm{P}$ & \multicolumn{2}{|c|}{ [95\% Conf. Interval] } \\
\hline $\begin{array}{c}\text { Faixa etária (30 anos ou } \\
\text { mais) }\end{array}$ & -1.42954 & 0.5563848 & -2.57 & $0.011 *$ & -2.526266 & -0.3328146 \\
\hline $\begin{array}{l}\text { Jornada de trabalho (até } \\
20 \text { horas) }\end{array}$ & 1.343262 & 0.3696094 & 3.63 & $0.000 *$ & 0.6147008 & 2.071822 \\
\hline $\begin{array}{c}\text { Horas extraclasse (1 a } 2 \\
\text { horas) }\end{array}$ & 1.965355 & 0.4078865 & 4.82 & $0.000 *$ & 1.161344 & 2.769366 \\
\hline $\begin{array}{c}\text { Horas extraclasse (3 a } 5 \\
\text { horas) }\end{array}$ & 2.331662 & 0.4142418 & 5.63 & $0.000 *$ & 1.515124 & 3.148201 \\
\hline $\begin{array}{c}\text { Horas extraclasse (6 a } 9 \\
\text { horas) }\end{array}$ & 1.694095 & 0.6066473 & 2.79 & $0.006^{*}$ & 0.498294 & 2.889897 \\
\hline $\begin{array}{c}\text { Horas extraclasse }(9 \text { a } \\
10 \text { horas })\end{array}$ & 2.807454 & 0.8178684 & 3.43 & $0.001 *$ & 1.195301 & 4.419606 \\
\hline $\begin{array}{c}\text { Horas extraclasse (mais } \\
\text { de } 10 \text { ) }\end{array}$ & 2.692951 & 0.8130797 & 3.31 & $0.001 *$ & 1.090237 & 4.295664 \\
\hline Moradia (alugada) & 0.8024543 & 0.3646553 & 2.2 & $0.029 *$ & 0.083659 & 1.52125 \\
\hline $\begin{array}{c}\text { Experiência na área (2 } \\
\text { anos) }\end{array}$ & 0.6706518 & 0.3459859 & 1.94 & $0.054 *$ & -0.011343 & 1.352647 \\
\hline $\begin{array}{l}\text { Renda familiar (11 } \\
\text { salários mínimos ou } \\
\text { mais) }\end{array}$ & 1.823306 & 0.6052008 & 3.01 & $0.003 *$ & 0.6303562 & 3.016256 \\
\hline _cons & 4.668412 & 0.3769181 & 12.39 & 0.000 & 3.925445 & 5.41138 \\
\hline
\end{tabular}

Nota. $* 95 \%$ de confiança; $* * 90 \%$ de confiança.

Coef. $=$ Coefficient, Std. Err. $=$ Standard Error, Conf. Interval $=$ Confidence Intervals

\section{Tabela 5}

Resumo dos resultados

\begin{tabular}{c|c|l}
\hline Disciplina & N & \multicolumn{1}{c}{ Interpretação dos Resultados } \\
\hline $\begin{array}{c}\text { Iniciação à } \\
\text { Pesquisa em } \\
\text { Contabilidade }\end{array}$ & 201 & $\begin{array}{l}\text { a) modernidade dos laboratórios de informática: relação positiva, quanto melhor o } \\
\text { laboratório, melhor o desempenho; b) estado civil: estudantes com status "solteiro" e } \\
\text { "casado" tendem a ter o melhor desempenho; c) faixa etária: discentes que têm entre } \\
18 \text { e 23 anos apresentam médias superiores aos das demais idades; d) horas } \\
\text { extraclasse: alunos que estudam ao menos uma duas ou três a cinco horas extraclasse } \\
\text { mostraram um desempenho superior aos que não estudam nenhuma; e) participação } \\
\text { econômica familiar: estudantes que trabalham e contribuem com a economia familiar } \\
\text { tendem a ter o desempenho inferior aos demais; f) experiência na área: estudantes } \\
\text { com experiência na área de sete a 12 meses foram os que obtiveram o menor } \\
\text { desempenho. }\end{array}$ \\
\hline $\begin{array}{c}\text { Contabilidade } \\
\text { Geral I }\end{array}$ & 207 & $\begin{array}{l}\text { a) coordenador de curso: relação positiva, quanto melhor a atenção recebida por parte } \\
\text { da coordenação, melhor o desempenho dos alunos; b) estado civil: alunos que } \\
\text { responderam "outros" para a pergunta acerca do estado civil, apresentaram um } \\
\text { desempenho superior aos dos demais grupos; c) faixa etária: estudantes de 30 anos ou } \\
\text { mais tendem a ter um desempenho inferior; d) jornada de trabalho: alunos que não } \\
\text { trabalham tendem a ter o menor desempenho; e) escola do ensino médio: alunos que } \\
\text { cursaram todo ou a maior parte do ensino médio em escola particular tendem a ter o } \\
\text { menor desempenho; f) membros da família: alunos que moram com outras pessoas, }\end{array}$ \\
\hline
\end{tabular}




\begin{tabular}{|c|c|c|}
\hline & & $\begin{array}{l}\text { que não são da família, tendem a ter o melhor desempenho; g) hora extraclasse: } \\
\text { discentes que não estudam nenhuma hora extraclasse tendem a ter o desempenho } \\
\text { inferior; } \mathbf{h} \text { ) participação econômica na família: alunos que não trabalham e recebem } \\
\text { ajuda financeira tendem a ter o menor desempenho. }\end{array}$ \\
\hline $\begin{array}{l}\text { Contabilidade } \\
\text { Geral II }\end{array}$ & 205 & $\begin{array}{l}\text { a) estado civil: estudantes divorciados tendem a ter o menor desempenho; b) faixa } \\
\text { etária: estudantes mais jovens (de } 18 \text { a } 23 \text { ) tendem a ter um desempenho superior aos } \\
\text { demais; c) hora extraclasse: discentes que não estudam nenhuma hora extraclasse } \\
\text { tendem a ter o desempenho inferior; d) turno: alunos do período noturno tendem a ter } \\
\text { o desempenho superior aos do matutino. }\end{array}$ \\
\hline $\begin{array}{l}\text { Elaboração das } \\
\text { Demonstrações } \\
\text { Contábeis }\end{array}$ & 137 & $\begin{array}{l}\text { a) estado civil: estudantes divorciados tendem a ter o menor desempenho; b) faixa } \\
\text { etária: estudantes de } 30 \text { anos ou mais tendem a ter um desempenho inferior enquanto } \\
\text { discentes que têm entre } 18 \text { e } 23 \text { anos apresentam médias superiores aos das demais } \\
\text { idades; c) horas extraclasse: alunos que se dedicam mais de } 10 \text { horas tendem a ter o } \\
\text { melhor desempenho; d) turno: estudantes do matutino tendem a ter as melhores } \\
\text { médias; e) membros da família: alunos que moram com mais de seis pessoas tendem } \\
\text { a ter o desempenho inferior aos demais. }\end{array}$ \\
\hline $\begin{array}{l}\text { Contabilidade e } \\
\text { Análise de } \\
\text { Custos }\end{array}$ & 214 & $\begin{array}{l}\text { a) projeto pedagógico do curso (PPC): relação positiva, os alunos com as melhores } \\
\text { notas nessa disciplina tendem a avaliar melhor o PPC; b) estado civil: estudantes } \\
\text { casados foram os que apresentaram as melhores médias; c) jornada de trabalho: } \\
\text { estudantes que trabalham } 20 \text { horas por semana tendem a ter um desempenho superior } \\
\text { aos que trabalham em tempo integral ( } 44 \text { horas por semana); d) membros da família: } \\
\text { alunos que moram com mais de seis pessoas tendem a ter o desempenho inferior aos } \\
\text { demais; e) horas extraclasse: discentes que não estudam nenhuma hora extraclasse } \\
\text { tendem a ter o desempenho inferior; f) renda familiar: alunos cuja renda familiar é de } \\
\text { cinco salários mínimos ou } 11 \text { salários mínimos ou mais tendem a ter o melhor } \\
\text { desempenho. }\end{array}$ \\
\hline $\begin{array}{l}\text { Contabilidade } \\
\text { Pública e } \\
\text { Orçamento } \\
\text { Governamental I }\end{array}$ & 224 & $\begin{array}{l}\text { a) faixa etária: estudantes de } 30 \text { anos ou mais tendem a ter um desempenho inferior; } \\
\text { b) jornada de trabalho: estudantes que trabalham } 20 \text { horas por semana tendem a ter } \\
\text { um desempenho superior aos que trabalham em tempo integral ( } 44 \text { horas por semana); } \\
\text { c) horas extraclasse: discentes que não estudam nenhuma hora extraclasse tendem a } \\
\text { ter o desempenho inferior; d) moradia: alunos que residem em residências alugadas } \\
\text { tendem a ter o melhor desempenho; e) experiência na área: discentes que têm } \\
\text { experiência de dois anos na área tendem a ter o melhor desempenho; f) renda familiar: } \\
\text { alunos cuja renda familiar é de } 11 \text { salários mínimos ou mais tendem a ter o melhor } \\
\text { desempenho. }\end{array}$ \\
\hline $\begin{array}{l}\text { Laboratório } \\
\text { Contábil }\end{array}$ & 119 & $\begin{array}{l}\text { a) faixa etária: discentes que têm entre } 18 \text { e } 23 \text { anos apresentam médias superiores } \\
\text { aos das demais idades; b) membros da família: alunos que moram com mais de seis } \\
\text { pessoas tendem a ter o desempenho inferior aos demais; c) hora extraclasse: discentes } \\
\text { que não estudam nenhuma hora extraclasse tendem a ter o desempenho inferior; d) } \\
\text { turno: alunos dos noturno tendem a ter o desempenho superior aos do matutino; e) } \\
\text { estilos de aprendizagem: discentes do estilo convergente obtiveram as melhores } \\
\text { médias. }\end{array}$ \\
\hline
\end{tabular}

\subsection{Discussão do Teste de Hipótese}

Com base nos resultados, é possível aceitar parcialmente a primeira hipótese da pesquisa, pois há relação estatisticamente significativa entre o desempenho dos alunos e os fatores pessoais: turno; escola do ensino médio; estado civil; experiência na área; horas de estudo extra classe; faixa etária; jornada de trabalho; membros da família; moradia; participação econômica familiar; e renda familiar. Os demais fatores - forma de ingresso, gênero e nível de instrução do responsável - não indicaram influência no desempenho acadêmico de discentes em nenhuma das disciplinas analisadas.

Os resultados reforçam os achados de: Amaro (2014), que indicam que existem relações significativas entre o desempenho dos alunos, a renda familiar mensal e as horas de estudos extraclasse; os de Win e Miller (2005) e Borges et al. (2017), que identificaram que o turno interfere no desempenho dos alunos; e de Uribe et al. (2011), que afirmam que a moradia interfere na nota dos alunos. Alunos que possuem uma melhor renda familiar tendem a ter as melhores 
notas, porém alunos que moram de aluguel também apresentaram desempenhos melhores, ficando contraditória a relação com a renda, portanto, recomenda-se novas pesquisas sobre este fator.

Em relação ao turno, os alunos do noturno demonstraram um melhor desempenho, entretanto foram analisados alunos de dois câmpus, sendo que um deles (Câmpus II) só oferta vagas para o período noturno. Com isso, apenas o Campus I possui alunos matriculados no período matutino, o que sugere novas investigações para confirmar esse achado. Geralmente, espera-se que os alunos do noturno tenham um desempenho inferior ao do diurno, porém muitos alunos do noturno trabalham durante o dia em atividades relacionadas à Contabilidade, auxiliando a relação entre a teoria e a prática. Conforme apresentado na estatística descritiva, dos 229 alunos, 47,2\% $(\mathrm{n}=108)$ trabalham em tempo integral, portanto, são alunos do turno noturno.

Mesmo que Amaro (2014) e Caiado e Madeira (2002) não tenham identificado relações significativas entre as variáveis "experiência na área", "escola do ensino médio" e "membros da família" e o desempenho dos alunos, neste estudo, foi identificada uma relação significativa entre essas variáveis e a nota dos alunos, o que sugere novas pesquisas. Os alunos que possuem experiência na área de Contabilidade demonstraram desempenho superior aos que nunca tiveram contato prático com a profissão, reforçando o resultado da relação entre o turno noturno e o desempenho, ou seja, muitos alunos do noturno trabalham em atividades da área Contábil.

Alunos que estudaram uma parte ou todo o ensino médio em escola particular evidenciaram ter um desempenho inferior aos demais, ou seja, neste estudo, ficou confirmado que alunos de escola pública apresentaram melhor desempenho. Para Baccaro (2014), o fato de ingressarem em uma universidade pública reconhecida, que é o caso da universidade onde está sendo realizado o estudo, eles esforçam-se e buscam um rendimento acadêmico elevado. Porém, esse resultado também é contraditório à variável renda familiar, mas está de acordo com a variável moradia, considerando que os alunos que estudam em escola pública e moram de aluguel apresentam uma renda menor. Portanto, esses resultados demandam estudos mais aprofundados.

Alunos que moram com outras pessoas que não são da sua família apresentaram melhor desempenho, enquanto os alunos que moram com seis ou mais pessoas tendem a ter um desempenho inferior. Esse resultado pode ser explicado pelo fato da universidade, onde foi realizado o estudo, receber alunos de outras cidades e também de outros estados. Esses alunos geralmente alugam moradias com outros estudantes e essa situação de residir com estranhos, estar longe da família e ter gastos para se manter (moradia, alimentação, viagens etc.) pode causar um sentimento de obrigação em obter resultados positivos no aprendizado.

Embora Ferreira (2015) tenha identificado em seu estudo que os alunos ingressantes por meio de alguma outra política que não seja o processo seletivo tradicional tendem a ter desempenho superior aos demais, o fator "forma de ingresso na instituição" não apresentou diferença estatisticamente significativa no desempenho dos alunos em nenhuma das disciplinas analisadas. Isto sugere que o ingresso dos alunos por meio de cotas sociais não interfere em seu desempenho. Durante a aplicação dos questionários e em conversas com os professores do Departamento de Ciências Contábeis, ficou evidente que os alunos ingressantes por meio de politicas sociais veem, no ensino superior, uma oportunidade para carreira e qualificação.

Neste estudo, em conformidade com Amaro (2014), Guney (2009) e Papageorgiou e Halabi (2014), não foram identificadas relações significativas entre o gênero e o desempenho dos alunos, ou seja, independentemente do gênero, os alunos apresentaram o mesmo desempenho. Embora Amaro (2014), Andrade e Corrar (2008) e Chow (2010) tenham identificado relações entre o desempenho dos alunos e o nível de instrução dos responsáveis, neste estudo, não houve influência dessa variável em nenhuma das disciplinas.

Mesmo que Amaro (2014) e Paiva e Lourenço (2011) tenham identificado influência estatisticamente significativa entre as variáveis "ambiente interno" e "desempenho", neste estudo, não foi identificada essa relação. Chamou atenção das pesquisadoras o fato de que, durante a aplicação do questionário, não foram poucos os alunos que perguntaram quem era o coordenador do curso e/ou o chefe do departamento. Portanto, muitos alunos nem sabem quem é o coordenador do curso e/ou o chefe do departamento e quais são as suas funções. Sendo assim, rejeita-se a 
segunda hipótese (H2). Ressalta-se que o construto "ambiente interno" não foi validado, e, com isso, os itens do fator foram analisados de forma isolada dentro do modelo de regressão. Considerando um nível de significância de 5\% (p<0,05), constatou-se que a variável "coordenador de curso" apresenta influência sobre a nota dos alunos da disciplina de Contabilidade Geral I, ou seja, quanto melhor a atenção recebida por parte da coordenação, melhor a nota do aluno.

Na hipótese 3 (H3), o objetivo foi verificar a influência entre estrutura e desempenho. A estrutura diz respeito às condições físicas para o funcionamento do curso de Graduação: adequação das salas de aulas; espaço físico das bibliotecas; qualidade do acervo bibliográfico; e modernidade dos laboratórios de informática. Assim como na pesquisa de Borges (2016), esse fator não apresentou influência no desempenho dos alunos, rejeitando-se, assim, a terceira hipótese. Embora não tenha sido apresentada relação positiva a partir dos testes estatísticos, os alunos relataram que as salas de aula e os laboratórios de informática apresentam uma grande ineficiência, especialmente quanto à tecnologia (computadores, projetor), à iluminação e a materiais diversos (cadeiras, mesas, quadro etc.).

A partir dos relatos dos alunos, não previstos no estudo, mas que serviram para um melhor entendimentos do assunto, cada item do fator foi analisado de forma isolada dentro do modelo de regressão. A partir da análise, foi identificada uma relação estatisticamente significativa entre o componente "modernidade dos laboratórios de informática" $(\mathrm{p}=0,008)$ e o desempenho dos alunos na disciplina de Iniciação à Pesquisa em Contabilidade. Sob a percepção dos alunos, quanto melhor o laboratório de informática, melhor seu desempenho, ou seja, confirma os relatos dos alunos quanto à ineficiência da modernidade dos laboratórios de informática.

Neste estudo, o fator "sistema técnico" refere-se aos recursos didáticos, ao software de ensino, ao acesso à internet e ao sistema acadêmico. Ao testar a hipótese 4 (sistema técnico e desempenho acadêmico), foi possível rejeitá-la, pois o fator não apresentou influência estatisticamente significativa sobre a nota dos alunos em nenhuma das disciplinas analisadas. Os resultados não confirmam os achados de: Borges (2016), que identificou uma relação entre as variáveis a um nível de significância de $10 \%$ ( $\mathrm{p}<0,10)$ em alunos do curso de Ciências Contábeis; Weathersbee (2008), que analisou a estrutura tecnológica com o desempenho dos alunos em disciplinas de matemática, leitura e ciências; e Amaro (2014), que também analisou a influência desse fator com o desempenho dos alunos de Contabilidade. Os resultados dessa variável também precisam ser aprofundados, considerando que os recursos didáticos podem envolver mais o aluno no processo de aprendizagem, melhorando o seu desempenho,

Quando analisada a hipótese 5 (H5), considerando um nível de significância de 5\%, o fator não apresentou influência na nota dos discentes. Porém, assim como no estudo de Borges (2016), quando aumentou para um nível de $10 \%$, mostrou ser um fator que interfere no desempenho dos alunos na disciplina de Contabilidade e Análise de Custos ( $\mathrm{p}=0,064)$, com isso não se rejeitou a H5, ou seja, em relação ao Projeto Pedagógico do Curso, quanto melhor a integração entre as disciplinas e quanto mais adequada a organização e carga horária de cada disciplina ofertada, melhor o desempenho do aluno.

Considerando um nível de significância de 5\%, o fator "estratégia do corpo docente" (H6) não apresentou nenhuma influência sobre a nota dos alunos. Com isso, rejeita-se a hipótese 6. Este estudo corrobora com os de Amaro (2014), que concluiu, em sua pesquisa, que a estratégia do corpo docente não interfere no desempenho dos alunos. Esse resultado causa estranheza, considerando que qualificação (titulação), domínio do conteúdo ministrado, práticas de ensino e interação com aluno, que são fatores importantes no processo de aprendizagem, não apresentam influência sobre o desempenho. Porém, a pesquisa de Borges (2016) identificou uma correlação negativa, ou seja, quanto maior a avaliação dos alunos no que diz respeito às estratégias do corpo docente, menor foi seu desempenho, o que sugere novas investigações.

Quanto à última hipótese (estilos de aprendizagem e desempenho), concluiu-se que existe diferença estatisticamente significativa $(\mathrm{p}<0,05)$ do estilo de aprendizagem convergente na nota dos alunos que cursaram a disciplina de Laboratório Contábil. Com isso, não se rejeita a hipótese 
7 (H7), visto que os resultados indicaram que os alunos desse estilo apresentaram médias superiores aos demais.

Diferente das outras disciplinas, que são teórico-práticas e teóricas, Laboratório Contábil é a única classificada como "prática" e suas técnicas são congruentes com as preferências do estilo convergente de aprendizagem, visto que a execução de ideias práticas e a tomada de decisões são dominantes em indivíduos com esse estilo, assim como possuem preferências em lidar com tarefas técnicas em vez de assuntos sociais e interpessoais, e gostam de novas ideias e simulações (Kolb, 1984; Kolb \& Kolb, 2005).

\section{CONSIDERAÇÕES FINAIS}

Existem diversos fatores que influenciam a aprendizagem e eles se inter-relacionam e acabam influenciando no desempenho acadêmico de um indivíduo. Tais fatores envolvem questões pessoais internas dos discentes, questões familiares e sociais e até questões relacionadas à instituição que o aluno frequenta (Suehiro, 2006). Outro fator associado ao desempenho acadêmico do estudante é o estilo de aprendizagem, sendo que identificá-lo propicia utilizar métodos de ensino e atividades que estimulem as diferentes preferências do aluno.

Primeiramente, foi necessário verificar a influência de fatores pessoais, especificamente as características dos discentes no seu desempenho acadêmico. Foi observada a relação desses fatores em cada uma das disciplinas analisadas e apenas "forma de ingresso", "nível de instrução do responsável" e "gênero" não apresentaram diferenças estatisticamente significativas no desempenho dos alunos. Vale ressaltar que o gênero, que é uma variável bastante utilizada em trabalhos nacionais e internacionais, aqui não mostrou nenhuma relevância. Muitas pesquisas apontaram relação entre ela e as notas dos alunos, enquanto também foram localizados estudos que, assim como este, não apresentaram.

Os alunos do turno noturno apresentaram desempenho estatisticamente superior nas disciplinas de Contabilidade Geral II e Laboratório Contábil, enquanto os alunos do matutino apresentaram médias superiores na disciplina de Elaboração das Demonstrações Contábeis. Apesar de os alunos do curso noturno geralmente trabalharem em período integral, supõe-se que o tempo para se dedicarem aos estudos seja menor. Por outro lado, esses alunos, frequentemente, trabalham na área contábil, facilitando a relação entre a teoria e a prática. Conclui-se que há necessidade de novas investigações.

O estado civil mostrou ser uma variável que influencia no desempenho dos alunos em cinco das sete disciplinas analisadas, sendo elas: Iniciação à Pesquisa em Contabilidade; Contabilidade Geral I; Contabilidade Geral II; Elaboração das Demonstrações Contábeis; Contabilidade; e Análise de Custos. No geral, os estudantes com status de divorciados apresentaram médias inferiores. Alunos cuja jornada de trabalho corresponde a 44 horas semanais apresentam desempenho inferior, quando comparado a alunos que trabalham com uma carga horária reduzida. Ademais, os discentes que têm a preocupação em trabalhar e contribuir com as despesas familiares apresentaram a menor média.

Alunos que cursaram a maior parte ou todo o ensino médio em escola particular obtiveram desempenho estatisticamente inferior quando comparados aos que estudaram em escola pública. Em conversas com os professores desses alunos, eles acreditam que estudantes que vieram de escolas públicas aproveitam a oportunidade de cursarem um ensino superior, dedicam-se mais e, consequentemente, apresentam um melhor desempenho. Além disso, os que responderam que não dedicam nenhuma hora extraclasse possuem notas estatisticamente inferiores aos que se dedicam ao menos uma hora extra semanal, o que mostra a importância em reforçar o conteúdo exposto em sala de aula. Os alunos que residem com mais de seis pessoas apresentaram, no geral, o menor desempenho. Em relação à faixa etária, os estudantes mais jovens (18 a 23 anos) tendem a ter as melhores médias e isso pode ser explicado pelo fato de o aluno estar acostumado com a rotina de estudos do ensino médio e ingressar direto na faculdade, ou ser uma delimitação da amostra em 
questão, o que sugere novas pesquisas para confirmar este achado. Estudantes cuja renda familiar é de 11 salários mínimos ou mais também apresentaram as melhores médias.

Também foi verificada a influência de fatores institucionais. A hipótese H5 (estratégia do PPC) foi confirmada, indicando que o PPC apresenta influência estatisticamente significativa no desempenho dos alunos, enquanto que a H2 (ambiente interno), a H3 (estrutura), a H4 (sistema técnico) e a H6 (estratégia do corpo docente) não foram confirmadas. Alguns estudos, como o de Ferreira (2015), apresentaram que o corpo docente possui uma relação significativa com o desempenho dos estudantes, o que sugere novas pesquisas e investigação quanto a essa variável.

Por fim, também foi verificada a influência dos estilos de aprendizagem no desempenho acadêmico dos discentes. Na disciplina de Laboratório Contábil, os alunos do estilo convergente apresentaram uma média de nota estatisticamente significativa superior quando comparados com os alunos dos demais estilos. Com isso, não se rejeita a $\mathrm{H} 7$, pois houve influência estatisticamente positiva e significativa dos estilos de aprendizagem na nota dos alunos. A partir desse achado, foi possível observar a relação da característica da disciplina com o estilo convergente. Alunos desse estilo de aprendizagem tendem a preferir atividades práticas, característica da disciplina em questão. Lizote et al. (2019), Oliveira et al. (2011) e Miranda et al. (2007) ressaltam a importância de técnicas de ensino apropriadas aos estilos de aprendizagem dos discentes.

A identificação dessas variáveis (turno, escola do ensino médio, estado civil, experiência na área, horas de estudo extraclasse, faixa etária, jornada, PPC) possibilita à coordenação do curso de Ciências Contábeis e aos docentes estudarem estratégias para melhorar resultado acadêmico dessas disciplinas, que são as que apresentam o maior índice de reprovação. A longo prazo, também espera-se contribuir para uma melhora nos índices do Enade e do Exame de Suficiência.

\section{REFERÊNCIAS}

Amaro, H. D. (2014). Influência de fatores contingenciais no desempenho acadêmico de discentes do curso de Ciências Contábeis de IFES. Dissertação de Mestrado, Universidade Federal do Paraná, Curitiba, PR, Brasil.

Andrade, J. X., \& Corrar, L. J. (2008). Condicionantes do desempenho dos estudantes de contabilidade: evidências empíricas de natureza acadêmica, demográfica e econômica. Revista de Contabilidade da UFBA, 1(1), 62-74. Recuperado de https://portalseer.ufba.br/index.php/rcontabilidade/article/view/2581/1824

Andriola, W. B. (2009). Fatores institucionais associados aos resultados do exame nacional de desempenho estudantil (ENADE): estudo dos cursos de graduação da Universidade Federal do Ceará (UFC). REICE. Revista Iberoamericana sobre Calidad, Eficacia y Cambio en Educación, 7(1), 22-49. Recuperado de http://hdl.handle.net/10486/661154

Araújo, E. A. T., Camargos, M. A., Camargos, M. C. S., \& Dias, A. T. (2014). Desempenho acadêmico de discentes do curso de Ciências Contábeis: uma análise dos seus fatores determinantes em uma IES Privada. Contabilidade Vista \& Revista, 24(1), 60-83. Recuperado de https://revistas.face.ufmg.br/index.php/contabilidadevistaerevista/article/view/1181

Arquero, J. L., Byrne, M., Flood, B., \& González, J. M. (2009). Motives, expectations, preparedness and academic performance: a study of students of accounting at a Spanish university. Revista de Contabilidad, 12(2), 279-299. doi: https://doi.org/10.1016/S11384891(09)70009-3

Ayeni, A. J., \& Adelabu, M. A. (2012). Improving learning infrastructure and environment for sustainable quality assurance practice in secondary schools in Ondo State, South-West, Nigeria. 
International Journal of Research Studies in Education, 1(1), 61-68. doi: http://dx.doi.org/10.5861/ijrse.2012.v1i1.20

Baccaro, T. A. (2014). A relação entre o desempenho no vestibular e o rendimento acadêmico no ensino superior: um estudo em uma universidade pública paulista. Tese de Doutorado, Universidade de São Paulo, Ribeirão Preto, SP, Brasil. Recuperado de https://teses.usp.br/teses/disponiveis///96/96132/tde-18072014-115113/pt-br.php

Ballester, C. P. M. (2012). Análise dos fatores que influenciam o desempenho acadêmico dos alunos de contabilidade por meio de modelos binários. Revista Brasileira de Gestão de Negócios, 14(45), 379. doi: http://dx.doi.org/10.7819/rbgn.v14i45.1080

Barahona, P. (2014). Factores determinantes del rendimiento académico de los estudiantes de la Universidad de Atacama. Estudios pedagógicos (Valdivia), 40(1), 25-39. http://dx.doi.org/10.4067/S0718-07052014000100002

Bergil, A. S. (2017). Feeding the ELT students' needs through Kolb's learning styles inventory. International Journal of Languages' Education and Teaching, 5(4), 42-54. doi: http://dx.doi.org/10.18298/ijlet.2263

Boezerooij, P. (2006). E-learning strategies of higer education institutions: an exploraty study into the influence of environmental contingencies on strategic choices of higher education institutions with respect to integrating e-learning in their education delivery and support processes. Tese de Doutorado, Center for Higher Education Policy Studies (CHEPS), Enschede, Holanda. Recuperado de https://www.researchgate.net/publication/254858556_Elearning_strategies_of_higer_education_institutions_an_exploraty_study_into_the_influence_ of_environmental_contingencies_on_strategic_choices_of_higher_education_institutions_wit h_respect_to_integra

Borges, I. M. T. (2016). Entendendo os diferentes: influência de fatores contingenciais e dos estilos de aprendizagem no desempenho acadêmico de discentes do curso de Ciências Contábeis. Dissertação de Mestrado, Programa de Pós-Graduação em Ciências Contábeis, Universidade Estadual de Maringá, Maringá, PR, Brasil. Recuperado de http://www.pco.uem.br/0-arquivos/dissertacoes/2016_iasmini-borges.pdf

Borges, M. S., Miranda, G. J., \& Freitas, S. C. (2017). A teoria da autodeterminação aplicada na análise da motivação e do desempenho acadêmico discente do curso de ciências contábeis de uma instituição pública brasileira. Revista Contemporânea de Contabilidade, 14(32), 89-107. doi: http://dx.doi.org/10.5007/2175-8069.2017v14n32p89

Branco, N. S. M. D. (2010). Estilos de aprendizagem de estudantes de enfermagem do $1^{o}$ ciclo de estudos: a influência da família e dos estilos de vida na forma preferencial de aprender. Dissertação de Mestrado, Mestrado em Ciências da Educação Especialização em Educação e Formação de Adultos, Universidade do Algarve, Faro, Portugal. Recuperado de https://sapientia.ualg.pt/bitstream/10400.1/2932/1/Disserta\%c3\%a7\%c3\%a3o\%20Mestrado\% 20S\%c3\%a9rgio\%20Branco.pdf

Caballero, J. L., Ruiz, J. A., Rodríguez, M. R., \& Ruiz, P. (2015). Factores determinantes del rendimiento académico universitario en el Espacio Europeo de Educación Superior. Innovar, 25(58), 159-175. doi: http://dx.doi.org/10.15446/innovar.v25n58.52440 
Caiado, J., \& Madeira, P. (2002). Determinants of the academic performance in undergraduate courses of the accounting. Munich Personel Repec Archive, (2199). Recuperado de http://mpra.ub.uni-muenchen.de/2199/

Campbell, M. M. (2007). Motivational systems theory and the academic performance of college students. Journal of College Teaching \& Learning (TLC), 4(7). doi: https://doi.org/10.19030/tlc.v4i7.156

Cepeda, R. R. (2018). Los modelos de aprendizaje de Kolb, Honey y Mumford: implicaciones para la educación en ciencias. Sophia, 14(1), 51-64. doi: http://dx.doi.org/10.18634/sophiaj.14v.1i.698.

Cerqueira, T. C. S. (2000). Estilos de aprendizagem em universitários. Tese de Doutorado, Universidade de Campinas, Campinas, SP, Brasil. Recuperado de http://www.repositorio.unicamp.br/handle/REPOSIP/253390

Cheng, F. F., Chiu, C. C., Wu, C. S., \& Tsaih, D. C. (2017). The influence of learning style on satisfaction and learning effectiveness in the asynchronous web-based learning system. Library Hi Tech, 35(4), 473-489. doi: http://dx.doi.org/10.1108/LHT-12-2016-0151

Chies, L., Graziosi, G., \& Pauli, F. (2014). Job opportunities and academic dropout: the case of the University of Trieste. Procedia Economics and Finance, 17, 63-70. doi: https://doi.org/10.1016/S2212-5671(14)00879-X

Chow, H. P. (2010). Predicción de éxito académico y bienestar psicológico en una muestra de estudiantes universitarios canadienses. Electronic Journal of Research in Educational Psychology, 21(8), 473-496. doi: http://dx.doi.org/10.25115/ejrep.v8i21.1382

Coffield, F., Moseley, D., Hall, E., \& Ecclestone, K. (2004). Should we be using learning styles? what research has to say to practice. Learning and Skills Research Centre. Recuperado de http://hdl.voced.edu.au/10707/64981

DeBello, T. C. (1990). Comparison of eleven major learning styles models: variables, appropriate populations, validity of instrumentation, and the research behind them. Reading, Writing, and Learning Disabilities, 6(3), 203-222. doi: https://doi.org/10.1080/0748763900060302

Dolado, J. J., \& Morales, E. (2009). Which factors determine academic performance of economics freshers? Some spanish evidence. Investigaciones Económicas, 33(2), 179-210. Recuperado de https://www.fundacionsepi.es/investigacion/revista.../May2009/v33i2a2.pdf

Douglass, J. A. (2005). How all globalization is local: countervailing forces and the influence on higher education markets. Higher Education Policy, 18(4), 445-473. doi: https://dx.doi.org/10.1057/palgrave.hep.8300096

El-Hmoudova, D., \& Milkova, E. (2015). Variations and frequencies in learning styles in a group of Czech English as foreign language learners. Procedia-Social and Behavioral Sciences, 182, 60-66. doi: https://doi.org/10.1016/j.sbspro.2015.04.738

Fagundes, J. A.; Soler, C. C.; Feliu, V.R.; Lavarda C. E. F. (2008). Proposta de pesquisa em contabilidade: considerações sobre a teoria da contingência. Revista de Contabilidade do Mestrado em Ciências Contábeis da UERJ, 13(2), 2-13. doi: ttps://doi.org/10.12979/rcmccuerj.v13i2.5545 
Felder, R. M., \& Silverman, L. K. (1988). Learning and teaching styles in engineering education. Engineering Education, 78(7), 674-681. Recuperado de https://eric.ed.gov/?id=EJ372622

Ferreira, M. A. (2015). Determinantes do desempenho discente no ENADE em cursos de Ciências Contábeis. Dissertação de Mestrado, Universidade Federal de Uberlândia, Uberlândia, MG, Brasil. Recuperado de epositorio.ufu.br/bitstream/123456789/12620/1/DeterminantesDesempenhoDiscente.pdf

Garkaz, M., Banimahd, B., \& Esmaeili, H. (2011). Factors affecting accounting students' performance: the case of students at the Islamic Azad University. Procedia-Social and Behavioral Sciences, 29, 122-128. doi: https://doi.org/10.1016/j.sbspro.2011.11.216

Guney, Y. (2009). Exogenous and endogenous factors influencing students' performance in undergraduate accounting modules. Accounting Education, 18(1), 51-73. doi: https://doi.org/10.1080/09639280701740142

Hair, J. F., Black, W. C., Babin, B. J., Anderson, R. E., \& Tatham, R. L. (2005). Análise multivariada de dados. Bookman Editora.

Hamann, E. V. (2011). Influência cultural sobre os estilos de aprendizagem dos estudantes de Ciências Contábeis do Distrito Federal: um estudo empírico sobre as abordagens de Hofstede e Kolb. Dissertação de Mestrado, Universidade de Brasília, Brasília, DF, Brasil. Recuperado de http://ppgcont.unb.br/images/PPGCCMULTI/mest_dissert_209.pdf

Hill, M. C., \& Epps, K. K. (2010). The impact of physical classroom environment on student satisfaction and student evaluation of teaching in the university environment. Academy of Educational Leadership Journal, 14(4), 65. Recuperado de https://digitalcommons.kennesaw.edu/facpubs/1308/

Hromcová, J., \& Agnese, P. (2018). Globalization, welfare, and the attitudes toward higher education. Economic Modelling, (November 2017), 1-15. doi: http://doi.org/10.1016/j.econmod.2018.05.013

Hsu, T. C. (2017). Learning english with augmented reality: do learning styles matter? Computers \& Education, 106, 137-149. doi: http://doi.org/10.1016/j.compedu.2016.12.007

Hurst, M. D. (2005). Schools eye future costs. Education Week, 24(35), 34-39. Recuperado de https://www.edweek.org/ew/articles/2005/05/05/35costs.h24.html

Kamal, S., Asrar, M., Younes, M., \& Chishti, A. (2014). Factors affecting academic performance of special students: a case of peshawar district. Ssrn. doi: http://doi.org/10.2139/ssrn.2755144

Keefe, J. W., \& Ferrell, B. G. (1990). Developing a defensible learning style paradigm. Educational Leadership, 48(2), 57-61. Recuperado de http://search.ebscohost.com/login.aspx?direct=true \&db=eric\&AN=EJ416436\&site=ehost-live

Kolb, D. A. (1984). Experiential learning: experience as the source of learning and development. Englewood Cliffs, N. J.: Prentice-Hall. 
Kolb, J. J., \& Funk, J. (2002). Kolb's learning style inventory: Issues of reliability and validity. Research on social work practice, 12(2), 293-308. doi: https://doi.org/10.1177/104973150201200206

Kolb, A. Y., \& Kolb, D. A. (2005). The Kolb learning style inventory - version 3.12005 technical Specifications. LSI Technical Manual, 1-72. Recuperado de https://www.researchgate.net/publication/241157771_The_Kolb_Learning_Style_InventoryVersion_31_2005_Technical_Specifi_cations

Kolb, A. Y., \& Kolb, D. A. (2008). Experiential learning theory: a dynamic, holistic approach to management learning education and development. Department of Organizational Behavior. Case. Western Reserve University. Working Paper. doi: http://doi.org/10.4135/9780857021038.n3

Leitão, M. (2006). Estilos de aprendizagem sob a ótica da psicologia evolucionista. Dissertação de Mestrado, Universidade Federal do Rio Grande do Norte, Natal, RN, Brasil. Recuperado de https://repositorio.ufrn.br/handle/123456789/17379

Lizote, A. A., Alves, C. S. R., Teston, S. F., \& Olm, J. W. (2019). Estilos de aprendizagem, desempenho acadêmico e avaliação docente. Revista Catarinense da Ciência Contábil, 18, 116. doi: http://dx.doi.org/10.16930/2237-766220192837

Lopes, W. M. G. (2002). ILS-inventário de estilos de aprendizagem de Felder-Saloman: investigação de sua validade em estudantes universitários de Belo Horizonte. Dissertação de Mestrado, Universidade Federal de Santa Catarina, Florianópolis, SC, Brasil. Recuperado de http://repositorio.ufsc.br/xmlui/handle/123456789/82278

Magdalena, S. M. (2015). The relationship of learning styles, learning behaviour and learning outcomes at the romanian students. Procedia-Social and Behavioral Sciences, 180, 1667-1672. doi: https://doi.org/10.1016/j.sbspro.2015.05.062

Mazzioni, S. (2013). As estratégias utilizadas no processo de ensino-aprendizagem: concepções de alunos e professores de Ciências Contábeis. Revista Eletrônica de Administração e TurismoReAT, 2(1), 93-109. doi: http://dx.doi.org/10.15210/reat.v2i1.1426

McCarthy, M. (2010). Experiential learning theory: from theory to practice. Journal of Business \& Economics Research, 8(5), 131-139. doi: https://doi.org/10.19030/jber.v14i3.9749

Miranda, G. J. (2011). Relações entre as qualificações do professor e o desempenho discente nos cursos de graduação em Contabilidade no Brasil. Tese de Doutorado, Universidade de São Paulo, São Paulo, SP, Brasil. Recuperado de https://www.teses.usp.br/teses/disponiveis/12/12136/tde-16032012-190355/pt-br.php

Nogueira, D. R. (2009). O impacto do estilo de aprendizagem no desempenho acadêmico: um estudo empírico com alunos das disciplinas de contabilidade geral e gerencial na educação à distância. Dissertação de Mestrado, Universidade Federal do Paraná, Curitiba, PR, Brasil. Recuperado de http://www.dominiopublico.gov.br/pesquisa/DetalheObraForm.do?select_action=\&co_obra=1 65503

Nogueira, D. R., Espejo, M. M. S. B., Reis, L. G., \& Voese, S. B. (2012). Estilos de aprendizagem e desempenho em educação a distância: um estudo empírico com alunos da s disciplinas de 
contabilidade geral e gerencial. Revista de Educação e Pesquisa em Contabilidade (REPeC), 6(1), 54-72. doi: https://doi.org/10.17524/repec.v12i4.1854

Oliveira, I. S. V. D. (2011). Os determinantes do desempenho acadêmico do corpo discente no ensino superior: evidências a partir da Universidade Federal da Paraíba. Dissertação de Mestrado, Programa de Pós-Graduação em Economia da Universidade Federal da Paraíba, João Pessoa, PB, Brasil. Recuperado de https://www.researchgate.net/publication/227473099

Paiva, M. O. A., \& Lourenço, A. A. (2011). Rendimento acadêmico: influência do autoconceito e do ambiente de sala de aula. Psicologia: Teoria e Pesquisa, 27(4), 393-402. doi: https://doi.org/10.1590/S0102-37722011000400002

Papageorgiou, K., \& K. Halabi, A. (2014). Factors contributing toward student performance in a distance education accounting degree. Meditari Accountancy Research, 22(2), 211-223. Recuperado de http://hdl.handle.net/2263/49369

Pereira, S. R. S. (2017). Determinantes do desempenho acadêmico: uma análise sobre as diferenças de cotistas e não cotistas. Tese de Doutorado, Universidade Federal da Bahia, Salvador, BA, Brasil. Recuperado de http://repositorio.ufba.br/ri/handle/ri/24148

Pérez, M. V., Pérez-López, M. C., \& Rodríguez-Ariza, L. (2011). Blended learning in higher education: students' perceptions and their relation to outcomes. Computers \& Education, 56(3), 818-826. doi: https://doi.org/10.1016/j.compedu.2010.10.023

Peter, S. E., Bacon, E., \& Dastbaz, M. (2010). Adaptable, personalised e-learning incorporating learning styles. Campus-Wide Information Systems, 27(2), 91-100. doi: http://doi.org/10.1108/10650741011033062

Polat, Y., Peker, A. A., Özpeynirci, R., \& Duman, H. (2015). The effect of learning styles of accounting education students on their performance: a field study. Procedia-Social and Behavioral Sciences, 174, 1841-1848. doi: http://doi.org/10.1016/j.sbspro.2015.01.846

Rodrigues, B. C. O. (2016). Análise da relação entre os atributos da coordenação de curso e o desempenho dos estudantes de Ciências Contábeis. Dissertação de Mestrado, Programa de PósGraduação em Ciências Contábeis, Universidade Federal de Uberlândia, Uberlândia, MG, Brasil. Recuperado de https://repositorio.ufu.br/handle/123456789/17902

Rodrigues, B. C. O., Resende, M. S., Miranda, G. J., \& Pereira J. M. (2016). Determinantes do desempenho acadêmico dos alunos dos cursos de Ciências Contábeis no ensino à distância. Enfoque Reflexão Contábil, 35(2), 139-153. https://doi.org/10.4025/enfoque.v35i2.30105

Santos, D. F., Gassner, F. P., Colauto, R., Antonovz, T., \& Correa, M. D. (2014). Estilos de aprendizagem: estudo com estudantes de Ciências Contábeis em uma universidade pública. Revista de Contabilidade da UFBA, 8(1), 37-53. Recuperado de https://portalseer.ufba.br/index.php/rcontabilidade/article/view/8583

Schmitt, C. S., \& Domingues, M. J. C. S. (2016). Estilos de aprendizagem: um estudo comparativo. Avaliação: Revista da Avaliação da Educação Superior (Campinas), 21(2), 361-386. https://dx.doi.org/10.1590/S1414-40772016000200004 
Silva, D. M. (2006). O impacto dos estilos de aprendizagem no ensino de contabilidade na FEARP/USP. Tese de doutorado, Universidade de São Paulo, São Paulo, SP, Brasil. Recuperado de https://www.teses.usp.br/teses/disponiveis/96/96133/tde-24012007-152550/pt-br.php

Soares, J. F. (2002). Escola eficaz: um estudo de caso em três escolas da rede pública de ensino do estado de Minas Gerais. Belo Horizonte: UFMG, 114. Recuperado de http://www.ccv.ufc.br/newpage/conc/seduc2010/seduc_dir/download/gestao1.pdf

Sousa, Z., Ferreira, M., \& Miranda, G. (2019). Teoria da atribuição de causalidade: percepções docentes e discentes sobre os determinantes do desempenho acadêmico. Advances in Scientific and Applied Accounting, 1(2), 40-58. Recuperado de https://asaa.anpcont.org.br/index.php/asaa/article/view/516

Stoll, L., Fink, D., \& Earl, L. (2005). It's about learning (and It's about time): what's in it for schools? Routledge Falmer, London.

Suehiro, A. C. B. (2006). Autoconceito e desempenho acadêmico em alunos de psicologia. Psicologia Argumento, 24(44), 65-72. doi: https://dx.doi.org/10.7213/rpa.v24i44.20135

Svinicki, M. D., \& Dixon, N. M. (1987). The Kolb model modified for classroom activities. College Teaching, 35(4), 141-146. doi: https://dx.doi.org/10.1080/87567555.1987.9925469

Triola, M. F. (2012). Introdução à estatística: atualização da tecnologia. In Introdução à estatística: atualização da tecnologia.

Truong, H. M. (2016). Integrating learning styles and adaptive e-learning system: current developments, problems and opportunities. Computers in Human Behavior, 55, 1185-1193. doi: https://doi.org/10.1016/j.chb.2015.02.014

Uribe, J. C. S., Gómez, L. M. C., \& Elorza, M. C. (2011). Identification of factors that affect the loss of student status using a logit survival model for discrete time data. Dyna, 79(171), 16-22. Recuperado de http://www.scielo.org.co/scielo.php?script=sci_arttext\&pid=S001273532012000100002

Weathersbee, J. C. (2008). Impact of technology integration in public schools on academic performance of Texas School Children. Tese de Doutorado, University-San Marcos, Texas, Estados Unidos da América.

Wentworth, D. K., \& Middleton, J. H. (2014). Technology use and academic performance. Computers \& Education, 78, 306-311. doi: https://doi.org/10.1016/j.compedu.2014.06.012

Win, R., \& Miller, P. W. (2005). The effects of individual and school factors on university students' academic performance. Australian Economic Review, 38(1), 1-18. doi: http://dx.doi.org/10.1111/j.1467-8462.2005.00349.x

Yanardöner, E., Kiziltepe, Z., Seggie, F. N., \& Sekerler, S. A. (2014). The learning styles and personality traits of undergraduates: a case at a state university in Istanbul. The Anthropologist, 18(2), 591-600. doi: https://doi.org/10.1080/09720073.2014.11891577 
Yousef, D. A. (2016). Learning styles preferences of statistics students: a study in the Faculty of Business and Economics at the UAE University. Quality Assurance in Education, 24(2), 227243. doi: https://doi.org/10.1108/QAE-01-2014-0004 